\title{
Brittle stars from the British Oxford Clay: unexpected ophiuroid diversity on Jurassic sublittoral mud bottoms
}

\author{
Timothy A.M. Ewin, ${ }^{1}$ and Ben Thuy ${ }^{2}$ \\ ${ }^{1}$ Department for Earth Sciences, The Natural History Museum, Cromwell Road, South Kensington, London, UK SW7 5BD, UK 〈t.ewin@nhm.ac.uk〉 \\ ${ }^{2}$ Natural History Museum Luxembourg, Department of Palaeontology, 24 rue Münster, L-2160 Luxembourg City, Luxembourg 〈bthuy@mnhn.lu〉
}

\begin{abstract}
Three new ophiuran species, Enakomusium whymanae n. sp., Aspidophiura? seren n. sp., and Ophiotitanos smithi n. sp., and an unnamed specimen assignable to the genus Dermocoma are described from the Callovian to Oxfordian Oxford Clay Formation of Great Britain. These determinations are based on new finds and a critical reassessment of historic specimens. The Oxford Clay ophiuroids represent two loose assemblages, one from the middle Callovian Peterborough Member and the other from the lower Oxfordian Weymouth Member. Both assemblages accord well with coeval midshelf mud bottom ophiuroid communities in terms of taxonomic composition and relative abundance of taxa. The British Oxford Clay ophiuroids are particularly significant as they are one of the rare instances where multiple species are represented, almost exclusively, by exceptionally preserved articulated skeletons. This provides an important window into the understanding of mid-Upper Jurassic ophiuroid paleobiology.
\end{abstract}

\section{Introduction}

Ophiuroid paleontology has undergone a remarkable revolution in the past few years. For many decades, most finds of fossil ophiuroids were dealt with as anecdotal oddities, worlds apart from the significance the group holds in modern marine environments (e.g., Stöhr et al., 2012). Until recently, comparatively few studies attempted a more systematic assessment of fossil ophiuroids, notable examples being Hess (1975) and references therein, and Kutscher and Jagt (2000). Driven by recent advances in the morphological interpretation of the ophiuroid skeleton, particularly with respect to microscopical features pertaining to the spine-bearing lateral arm plates (Martynov, 2010; Thuy and Stöhr, 2011), efforts have been made to explore the ophiuroid fossil record from a much broader perspective. Now that fossil ophiuroids are better understood as taxonomically assessable testimonies of the evolutionary history of a diverse, widespread, and ecologically significant group of extant marine invertebrates, their systematic study has gained new momentum.

Dissociated lateral arm plates preserved as microfossils were recently identified as the most promising source of evidence to systematically assess the ophiuroid fossil record (Thuy and Stöhr, 2011; Thuy et al., 2012; O'Hara et al., 2014). They can be very abundant and represent a time-averaged, taphonomically unbiased record of the ophiuroid assemblages at a given time and are therefore the most likely candidates to reflect the true ophiuroid paleobiodiversity as exhaustively as possible (Thuy, 2013, 2015). Fossils of articulated ophiuroid skeletons, by contrast, are rare finds bound to exceptional depositional conditions and therefore provide highly patchy glimpses into the fossil record of the group.

The fossil ophiuroids collected from the British Oxford Clay over the past 170 years are, however, a remarkable exception to this general pattern. In fact, the specimens known to date almost exclusively consist of articulated skeletons and, indeed, provide insights on the ophiuroid faunal spectrum otherwise only expected from dissociated lateral arm plates. The current state of knowledge on the Oxford Clay ophiuroids is limited to the original descriptions of Amphiura pratti Forbes, 1844 and Ophioderma weymouthiense Damon, 1880, later revised by Hess (1964), of ophiuroid occurrences (Wright, 1880; Martill and Hudson, 1991) and a preliminary report on a new species (Ewin and Thuy, 2015).

The post-Paleozoic ophiuroid fossil record has received increasing attention over the past few decades, beginning with the pioneering work of Hans Hess (summarized by Hess, 1975). With few exceptions, however, most studies focused on taxonomically assessing post-Paleozoic ophiuroid paleobiodiversity, given the huge gaps still existing (e.g., Thuy, 2013) and hampering a comprehensive fossil-based exploration of the ophiuroid evolutionary history. Here, we provide an exhaustive systematic assessment of the ophiuroid material currently known from the British Oxford Clay Formation, including both historical finds and new discoveries, and attempt to put the studied material in a broader context in terms of paleobiology and systematics.

\section{Materials and methods}

The material studied comprises the holotype of Amphiura pratti and the additional conspecific specimen illustrated by Wright (1880), the neotype of Ophioderma weymouthiense and the associated specimens from the same locality (Hess, 1964), a previously undescribed single specimen collected ex situ from the Fleet, near Weymouth, Dorset, an undetermined ophiuroid figured by Martill and Hudson (1991), and the recently collected lot of specimens preliminarily described by Ewin and Thuy (2015). 
Almost all material consists of articulated skeletons or parts of skeletons collected as macrofossils. The series of specimens described by Ewin and Thuy (2015) furthermore includes numerous articulated parts of disks and arms as well as dissociated skeletal plates collected by bulk sieving in water using a $150 \mu \mathrm{m}$ mesh. Thanks to the mostly clayey matrix, most studied specimens are exquisitely preserved showing original stereom structures.

The material was examined using scanning electron microscopy (SEM), in case of the larger specimens using a Leo LV1455VP low-pressure environmental SEM without coating, and in case of the smaller ones using a JEOL Neoscope JMC-5000 with gold coating. Terminology followed Stöhr et al. (2012) and Thuy and Stöhr (2011). Lateral arm plates are abbreviated as LAPs in the following sections of the manuscript.

Repositories and institutional abbreviations.-All material is housed in the Natural History Museum London (NHMUK) with the exception of the holotype of $A$. pratti, which is housed at the Geological Survey Museum (BGS), and the specimen figured by Martill and Hudson (1991), which is housed in Leicester University Geology Collections (LEIUG).

\section{Oxford Clay ophiuroid localities, stratigraphy, geology, and taphonomy}

In England, the Oxford Clay Formation, middle Callovianlower Oxfordian, crops out along a southwest/northeast trending band (Fig. 1) from the south coast of Dorset near Weymouth, through Wiltshire, Gloucestershire, and central England and

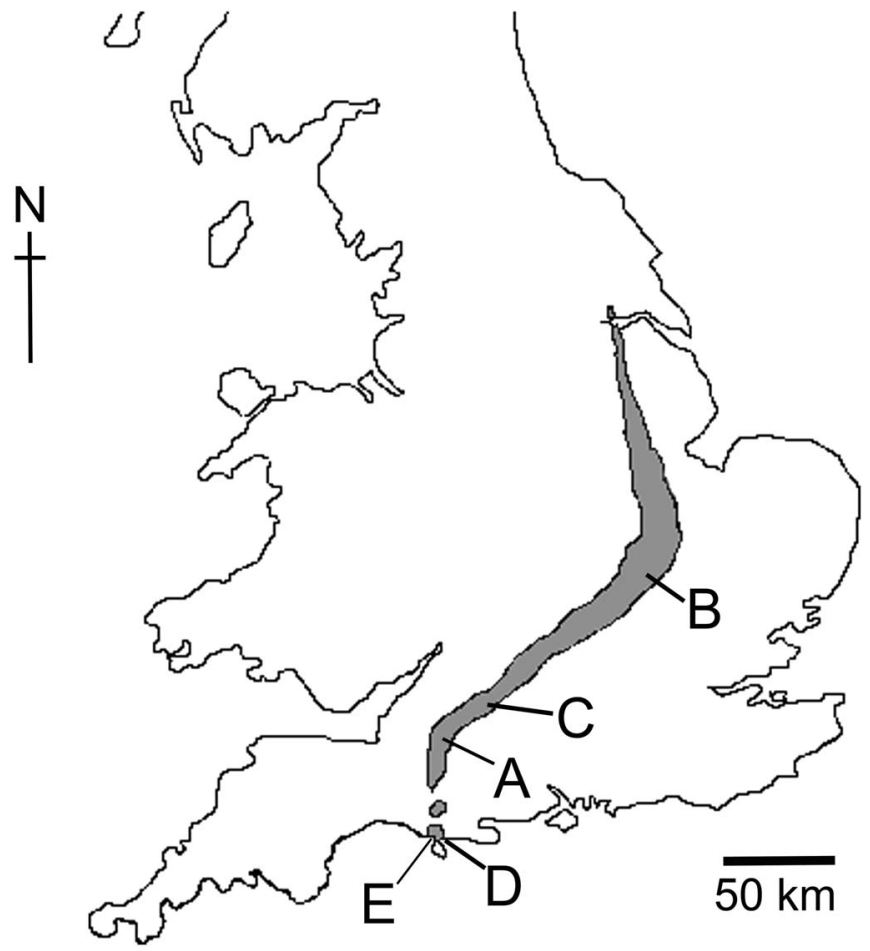

Figure 1. Map showing the outcrop surface of the Oxford Clay Formation in Great Britain and the positions of the ophiuroid localities (A: Ophiotitanos smithi, Ophioplax pratti; B: Enakomusium indet. C: Enakomusium whymanae, Aspidophiura seren; D: Enakomusium weymouthiense; E: Dermocoma sp.). into Lincolnshire and Yorkshire, where it again meets the coast at Scarborough (Cox and Sumbler, 2002). Owing to the relatively unconsolidated nature of the formation, natural outcrops are only seen in areas of constant erosion, essentially coastal areas (Weymouth). However, the Oxford Clay Formation has been exposed in numerous inland areas at different times owing to various excavation activities. Several of these activities have produced the ophiuroid specimens that form the basis of this study (Fig. 1) and include railway line construction (Cheltenham and Christian Malford, Wiltshire in the 1840s; Wilby et al., 2008), quarrying of overlying Pleistocene gravels (Coln Quarry, Gloucestershire; Dr. N. Hollingworth, personal communication, 2015), and clay extraction for brick manufacture (Westaway et al., 2015).

The Callovian of southern and central England represents a time of steady sea level rise into the Oxfordian (Wright and Cox, 2001). This is reflected in the widespread and laterally consistent deposition of the Oxford Clay, which has a silty/sandy base grading into fine and fissile clays and shales with a high organic content. The seas around Britain during the CallovianOxfordian were generally warm and clear. Land was located approximately $50-100 \mathrm{~km}$ away from any of the studied localities and lay mostly to the north, west, and east (Cox and Sumbler, 2002). These lands were presumably the source of intermittent pulses of sediment that buried the ophiuroids.

The Oxford Clay Formation is subdivided into Taxon-range biozones and subzones using ammonites (Cox and Sumbler, 2002) and comprises three members, the lowest Peterborough Member, the middle Stewartby Member (both Callovian), and the upper Weymouth Member (Oxfordian). The Oxford Clay has been the subject of many detailed studies owing to its economic importance as a source of self-firing brick clay and its abundant and exquisitely preserved fossils (Westaway et al., 2015; Martill and Hudson, 1991). The three members of the Oxford Clay Formation are remarkably consistent across their outcrop of over $200 \mathrm{~km}$, which is indicative of its deposition during a wide transgression (Cox and Sumbler, 2002). Figure 2 shows the stratigraphy of the Oxford Clay in central and southern England and the position of the ophiuroids studied herein.

Ophiuroids are known from the Peterborough Member and probably (see the following) the Weymouth Member of the Oxford Clay Formation. None have conclusively been found in the Stewartby Member, which is regarded as generally poor in shelly fossils (Cox and Sumbler, 2002). The Kosmoceras jason Taxon-range Biozone of the Peterborough Member has long been known as a source of numerous, exquisitely preserved fossils, particularly from sites near Christian Malford (mainly cephalopods and fish; Wilby et al., 2008) and around the Peterborough brick pits where numerous marine reptiles were collected by the Leeds brothers but which is also known for its abundant invertebrate fauna (Martill and Hudson, 1991). The high diversity and organic content of the sedimentary rock of this member are attributed to high productivity (MacQuaker, 1994; Hudson et al., 1994; Martill et al., 1994). It is the Peterborough Member that four of the species (from three different localities) described herein come from. The other two species probably come from the Weymouth Member ("upper Oxford Clay"-lower Oxfordian) around the town of Weymouth, which is also well known for its fossil mollusk fauna (Cox and 


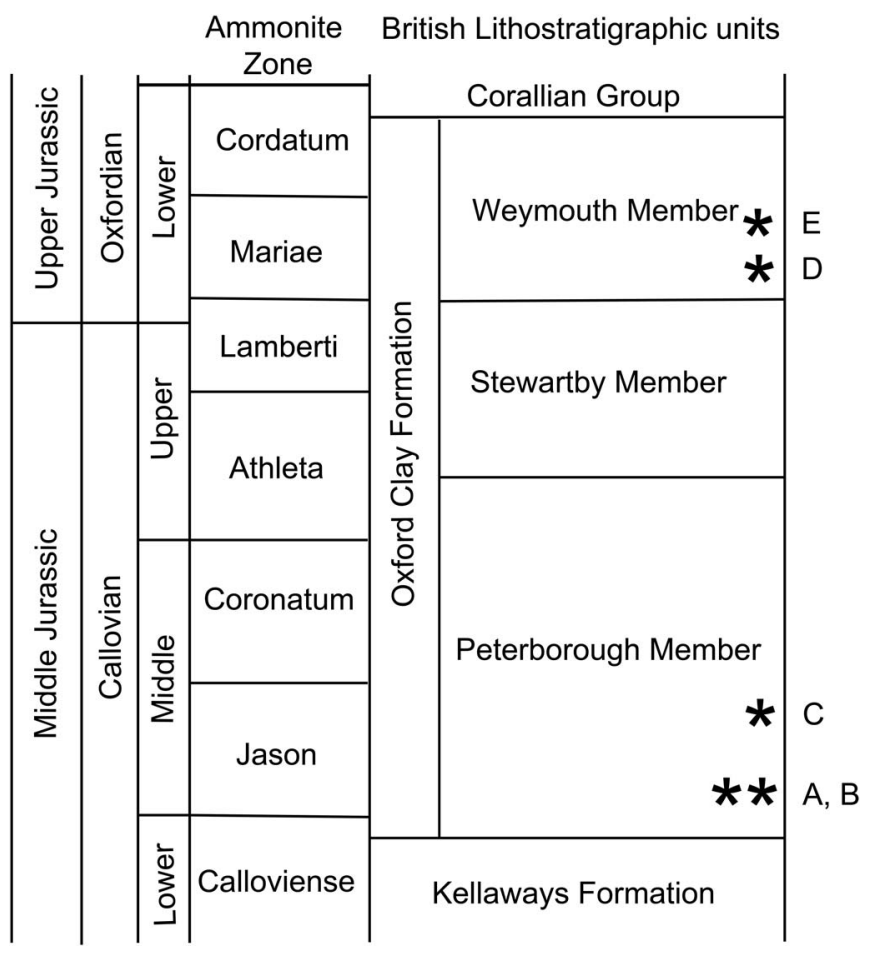

Figure 2. Stratigraphic chart of the Oxford Clay Formation with ammonite zones, lithological units, and the positions of the ophiuroid localities (A: Ophiotitanos smithi, Ophioplax pratti; B: Enakomusium indet. C: Enakomusium whymanae, Aspidophiura seren; D: Enakomusium weymouthiense; E: Dermocoma sp.).

Sumbler, 2002). The geologies of the five different localities are discussed individually in the following. Subdivision lettering matches that used in Figures 1, 2.

A: Christian Malford, NE Chippenham, Wiltshire. The specimens (Ophiotitanous smithi n. sp. and Ophioplax prattii n. comb.) studied herein are presumed to be from the Kosmoceras phaeinum Subzone, Peltoceras athleta Zone, upper part of the Peterborough Member, Oxford Clay Formation, upper Callovian, Middle Jurassic. While the precise localities of these specimens are unknown, they are both associated with the Christian Malford Lagerstätten. This famous site produced large numbers of fossils with spectacular soft tissue preservation, principally of cephalopods and fish, during the Victorian era (1840s-1850s). However, the precise site of the bed was kept secret by the Victorian collectors, and as such, locality names such as "Christian Malford" and "Chippenham" are all that is known. However, owing to the significance of these fossils, much work was recently undertaken to relocate the site, and it was indeed "rediscovered" in 2008 (Wilby et al., 2008). Analysis of the ammonites returned from cores identified the site as belonging to the Kosmoceras phaeinum Subzone, from the Upper Peterborough Member (Wilby et al., 2008). While no ophiuroids were collected during this recent work, it is assumed that these Victorian collections came from somewhere close to these localities and horizons.

The lack of precise locality detail and the extraction of specimens from the matrix leave little scope to assess the taphonomy. It is however assumed that burial must have been rapid (obrution?) as the specimens are preserved in articulation with minimal subsequent disturbance by burrowers (exclusion by sediment anoxia?). The environment outlined by Wilby et al. (2004) for the preservation of soft-tissue coleoids (a very soft "soupy" anoxic sea floor) at Christian Malford, however, appears to be unfavorable for ophiuroids. As such, it is unlikely that the ophiuroids are from exactly the same horizon. That said, it is known that there was a high degree of variability in sea floor conditions at this time (Duff, 1975), so it does not preclude these specimens from occurring close (geographically and stratigraphically) to the Christian Malford Lagerstätte.

B: Stewartby quarry, Stewartby Brickworks, Bedford, Bedfordshire, UK Bed 6a (of Duff, 1974), Lower Oxford Clay, Kosmoceras medea Subzone, jason Zone (Callovian), Middle Jurassic. Collected by Keith Duff in 1970 from the base of the Peterborough Member, the ophiuroids (Enakomusium indet.) were found in a lens, which faded away in all directions and was $40 \mathrm{~cm}$ above the base bed $6 \mathrm{~A}$, in the medea Subzone of the jason Zone (Duff, 1974). The sediment preserving the specimens is olive-green, rather well-laminated, shaley clay, belonging to the deposit-feeder bituminous shales biofacies of Duff (1975). It is in a facies Duff (1975) described as at the restricted end of this biofacies and was associated with a fauna dominated by Bositra and Procerithium, with subsidiary Pinna, Dicroloma, and Meleagrinella with rare nuculaceans (Palaeonucula and Mesosacella). While preservation of the ophiuroid skeleton is poor (stereome lost), the specimens consist of articulated individuals. Both oral and adoral surfaces are uppermost on the slab surface in different specimens that are located at slightly different levels throughout, with some overlapping one another. This is suggestive of short transportation and rapid deposition as occurs during an obrution event. There is no evidence of arm loss and regeneration.

C: Coln Quarry, Lechlade, Gloucestershire, UK 51.6951º N, $1.7372^{\circ} \mathrm{W}$. The specimens (Enakomusium whymanae n. sp. and Aspidophiura seren n. sp.) studied were collected by Ms. Janet Whyman from ex situ material that had been extracted from a drainage trench in the base of the quarry. The fossils originate from a fissile gray shaley clay from the jason Zone, lower Peterborough Member, lower Oxford Clay, Callovian, upper Middle Jurassic. Apart from unpublished observations and logs compiled by Dr. N. Hollingworth, the Oxford Clay at Coln Quarry is poorly known. Much about this locality is therefore here inferred by comparison with the better-known type locality for the Peterborough Member, near Peterborough, Bedfordshire, which was heavily studied in the early 1990s (e.g., Hudson and Martill, 1991, 1994; Hudson et al., 1994; MacQuaker, 1994; Martill et al., 1994). The Peterborough Member at Coln is composed of a richly fossiliferous series of shales and calcareous mudstones, dominated by the ammonite Kosmoceras and by bivalves and gastropods (N. Hollingworth, personal communication, 2015) although contextual material collected (by J. Whyman, 2008) along with the ophiuroids at Coln Quarry includes teleost and shark teeth, short sections of isocrinid pluricolumnals, crustaceans, brachiopods, and belemnites. The environment of the Oxford Clay surrounding Coln Quarry has been interpreted as a warm, shallow-shelf sea with normal salinity. Land probably lay close by, to the northeast, where marginal marine facies are seen in the East Midlands (Cox and Sumbler, 2002). The bottom waters of the sea are suspected to have been euroxic, with the high carbon content attributed to high 
productivity (MacQuaker, 1994; Martill et al., 1994) as at the type locality for the Peterborough member.

Specimens are randomly but densely distributed through a layer of rock approximately $2 \mathrm{~cm}$ thick, some overlapping each other. Both oral and adoral surfaces of different specimens are visible on the same bedding plain. Many individuals are articulated, missing only arm tips; however, most remains consist of long articulated sections of arm and isolated discs. There are also some isolated plates. All articulated material pertains to Enakomusium whymani $\mathrm{n}$. sp. as does most of the disarticulated material; however, the latter also includes lateral arm plates of Aspidophiura seren $\mathrm{n}$. sp. This suggests that the articulated E. whymani $\mathrm{n}$. sp. were gregarious and buried after short transportation by an obrution event. The isolated material appears to be well preserved but suggests that the ophiuroids were disarticulated before deposition. It seems likely Aspidophiura seren n. sp. and E. whymani $\mathrm{n}$. sp. coexisted but were not intimately associated (as the former has not been found articulated).

The arms of articulated $E$. whymani $\mathrm{n}$. sp. specimens were not noted to be regenerating. This may be because predation pressure was low, but it is as likely due to the preservation and extraction of the majority of the specimens (most have disarticulated arms owing to being extracted through bulk sieving).

D: The locality of the type material (Enakomusium weymouthiense [Damon, 1880]) is not specifically recorded and therefore may come from either Radipole Backwater or Ham Cliff, Weymouth, Dorset. Similarly preserved specimens, in similar matrix, from Weymouth, are recorded as coming from either 'a Railway cutting near The Backwater' or simply just 'The Backwater.' It is here assumed that all these specimens most likely come from the Radipole Backwater area. Unfortunately, the Oxford Clay at the Radipole Backwater is no longer accessible. The outcrop at Ham Cliff, however, was studied by Page (2002), who, from ammonites, established that the succession there straddles the Callovian/Oxfordian boundary. It includes fossils from the Quenstedtoceras lamberti lamberti Subzone to the Cardioceras (Scarburgiceras) scarburgense Subzone and therefore includes both the top of the Stewartby Member and the base of the Weymouth Member. Unfortunately, there is little lithological distinction between the members at this site, and as the precise locality and horizon of the ophiuroid specimens is not known, it remains ambiguous as to where these specimens are from. They are, however, younger than the deposits at Coln, Christian Malford, and Peterborough.

The rocks that preserve the ophiuroids are coarse light gray/green cross-bedded silts that are burrowed. Numerous individuals (10 individuals on the surface of a slab measuring $110 \mathrm{~mm} \times 150 \mathrm{~mm}$ ) are found on single slabs of rock, displaying both dorsal and ventral surfaces with several overlapping and being separated by thin wedges of sediment. Most specimens are composed of disks and several arms although often the distal sections are missing. Long sections of isolated arms are also present. This suggests burial in the medial-distal part of an obrution event, where the brittle stars were transported a short distance and buried rapidly.

Several articulated specimens display arms in states of regeneration (smaller and shorter than other arms; approximately 1:10 specimens are regenerating). While this does not equate to a high degree of predation pressure, it is notable because it is unobserved in other British Oxford Clay ophiuroids. However, this is likely due to sample size and differing preservation in other locations rather than a meaningful biological signal.

E: The Fleet, Weymouth, Dorset. The single specimen (Dermocoma sp.) recovered from this locality has been completely removed from the matrix, and as such, all lithological context has been lost. The Fleet is a large lagoon (over $5 \mathrm{~km}$ long) that stretches westward from Weymouth where both the Weymouth and Stewartby members of the Oxford Clay Formation are known to occur. However, the specimen studied herein is coated in pyrite, which hints that it belongs to the more fossiliferous Weymouth Member as ammonites between Tidmore Point and Weymouth are similarly preserved (Cox and Page, 2002).

\section{Systematic paleontology}

Discussion.-Since the classification by Smith et al. (1995) was recently shown to be untenable (O'Hara et al., 2014; Thuy and Stöhr, 2016), we leave the species described herein in open nomenclature above genus level, suggesting an assignment with respect to the clades of O'Hara et al. (2014) whenever possible and providing descriptions enabling inclusion in subsequent phylogenetic studies (e.g., Thuy and Stöhr, 2016).

$$
\begin{gathered}
\text { Class Ophiuroidea Gray, } 1840 \\
\text { Clade A of O'Hara et al. (2014) } \\
\text { Genus Enakomusium Thuy, 2015 }
\end{gathered}
$$

Type species.—Ophioderma weymouthiense Damon, 1880, by original designation.

Diagnosis (emended from Thuy, 2015).-Ophiuroid genus with robust overall skeletal plating; thick disk scales devoid of removable granules; leaf-like oral papillae, completely separated; genital slit devoid of papillae; arms with small and mostly noncontiguous dorsal and ventral arm plates at least in proximal to median arm segments; lateral arm plates thick, robust, rounded rectangular; outer proximal edge commonly with spurs and paralleled by a conspicuous, deep furrow; spine articulations integrated into outer surface stereom, moderately large and prominent, and composed of a round muscle opening proximally tightly encompassed by a small, thin, commonly denticulate ridge and distally separated from a slightly smaller nerve opening by a large, commonly curved vertical ridge; arm spines commonly longer than half an arm segment; tentacle openings developed as deep, ventralward, pointing notches in proximal to median arm segments and as distalward-pointing within-plate perforations in median to distal arm segments.

\section{Enakomusium whymanae new species} Figures 3, 4

\section{Holotype.-NHMUK EE 16205.}

Diagnosis.—Relatively small species of Enakomusium with pairs of radial shields separated interradially by single plates similar in shape and size to radial shields; LAPs comparatively thin, with a weak constriction but devoid of spurs on the outer 

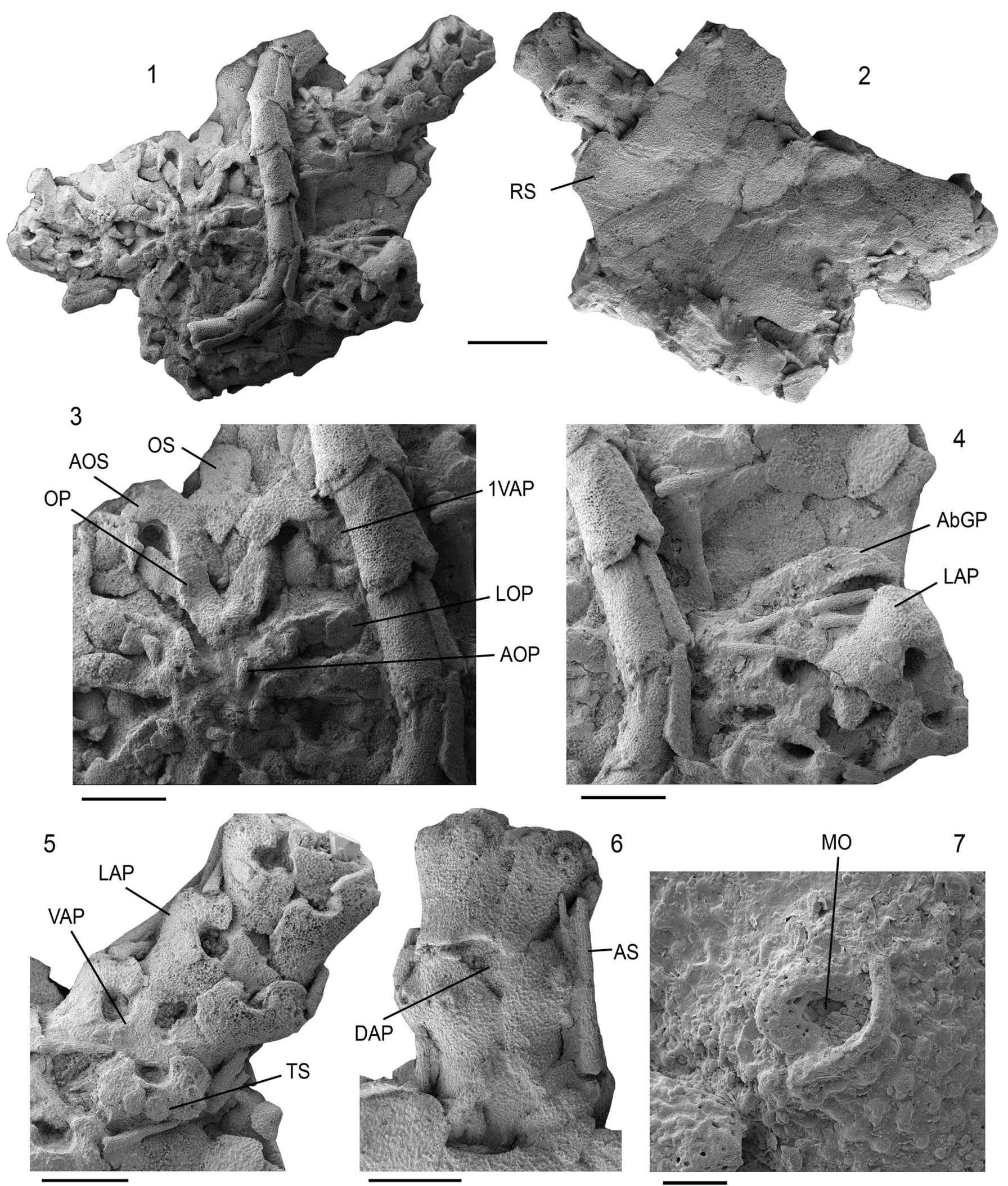

Figure 3. Enakomusium whymanae n. sp., NHMUK EE 16205 (holotype), Coln Quarry, Lechlade, Gloucestershire, UK 51.6951N, 1.7372W; ex situ layer of fissile gray shaley clay from the jason Zone, Peterborough Member, lower Oxford Clay, Callovian, late Middle Jurassic. (1) Ventral side of disk; (2) dorsal side of disk; (3) detail of mouth plating; (4) detail of ventral interradius; (5) ventral side of proximalmost arm segments; (6) dorsal side of proximalmost arm segments; (7) detail of spine articulation. (1, 2) Scale bar $=1 \mathrm{~mm} ;(\mathbf{3 - 6})$ scale bars $=500 \mu \mathrm{m}$; (7) scale bar $=50 \mu \mathrm{m}$. AbGP $=$ abradial genital plate; $\mathrm{AOP}=$ apical oral papilla; $\mathrm{AOS}=$ adoral shield; $\mathrm{AS}=\mathrm{arm}$ spine; $\mathrm{DAP}=$ dorsal arm plate; LAP = lateral arm plate; LOP = lateral oral papilla; $\mathrm{MO}=$ muscle opening; $\mathrm{OP}=$ oral plate; $\mathrm{OS}=$ oral shield; $\mathrm{RS}=$ radial shield; $\mathrm{TS}=$ tentacle scale; $\mathrm{VAP}=$ ventral arm plate; $1 \mathrm{VAP}=$ first ventral arm plate. 
proximal edge; large, prominent spine articulations not sunken into depressions and bearing conical, pointed arm spines exceeding the length of an arm segment.

Occurrence.-Coln Quarry, Lechlade, Gloucestershire, UK $51.6951^{\circ} \mathrm{N}, 1.7372^{\circ} \mathrm{W}$; ex situ layer of fissile gray shaley clay from the jason Zone, Peterborough Member, lower Oxford Clay, Callovian, late Middle Jurassic.

Description of holotype.-EE 16205 (Fig. 3) is an articulated disk (4.58 $\mathrm{mm}$ disk diameter) exposing both dorsal and ventral sides and with proximal segments of one arm preserved; ventral side covered by an arm fragment comprising eight median to distal segments and belonging to the holotype or to another specimen of the same species; dorsal side of the disk covered in its central part by few small, round, imbricate and moderately thick scales and a slightly larger circular central primary plate; remaining dorsal side of the disk covered by large, rounded isosceles-triangular radial shields (Fig. 3.2) accounting for approximately two-thirds of the disk radius joined in pairs over their entire length and separated interradially by a single plate similar in shape to the radial shields but slightly narrower; no removable granules or spines or conspicuous stereom ornamentation discernible on the dorsal disk plates and scales.

Ventral side of disk with relatively few interradial scales similar in shape and size to the dorsal disk scales, devoid of removable granules or spines. Genital slit extending over at least half of the disk radius; no genital papillae discernible; abradial genital plate (Fig. 3.4) length approximately four times width, with longitudinal ridge but devoid of perforation on exposed side. Oral shield (Fig. 3.3) arrow-shaped, with pointed, acute proximal angle, concave lateral edges, and rounded rectangular distal portion; adoral shields (Fig. 3.3) comparatively broad, with wide distal portion encompassing almost half of the second oral tentacle opening; proximal tips of adoral shields meeting in front of oral shield; second oral tentacle pore (Fig. 3.3) opening inside mouth slit; oral plates stout and wide; first ventral arm plate radially compressed pentagonal, wider than long, with obtuse distal angle, pointed lateral angles, and rounded rectangular proximal edge; lateral oral papillae (Fig. 3.3) fully separated but contiguous, rounded rectangular except for pointed distal-most papilla, second distal-most papilla largest, remaining papillae continuously decreasing in size toward the dental plate; single, short, conical apical oral papilla, slightly smaller than neighboring lateral oral papillae; teeth not exposed.

Only proximal arm segments preserved (note that the median to distal arm portion covering the ventral side of the holotype is ignored here as it might well belong to another individual), segments nearly as long as wide; LAPs with weak constriction and coarsely meshed outer stereom with slightly enlarged trabecular intersections; spine articulations on elevated part of distal LAP portion, at some distance from the distal edge of the plate; spine articulations (Fig. 3.7) relatively large, evenly distributed over the entire distal portion of the LAP, with a dorsalward increase in size of the spine articulations and in the distance separating them; dorsal-most spine articulation visible in dorsal view; spine articulation composed of a large round muscle opening proximally bordered by a thin, irregularly denticulate vertical ridge and distally encompassed by a wider, more strongly protruding, smooth, semicircular and oblique vertical ridge; nerve opening slightly smaller than muscle opening, distally bordering the semicircular ridge; arm spines (Fig. 3.6) conical, pointed, with rough longitudinally reticulate outer surface, slightly longer than one arm segment; ventral edge of lateral arm plates with deep tentacle notch, distally encompassed by a thinned ventro-distal edge of the lateral arm plate. Ventral arm plates (Fig. 3.5) widest distally, with straight distal edge, deeply concave latero-proximal edges, and pointed proximal tip, separated by lateral arm plates on all exposed segments; tentacle openings large, covered by two oval, nearly equal-sized tentacle scales, developed as between-plate openings in all preserved arm segments. Dorsal arm plates (Fig. 3.6) small, fan-shaped, with right proximal angle and convex distal edge, widely separated by lateral arm plates.

Paratype supplements.-EE 16206 (Fig. 4.1) is an articulated disk (4.63 mm disk diameter) exposing both ventral and dorsal sides; ventral disk morphology well in agreement with that of holotype; dorsal disk plating better preserved than in holotype, with clearly radial shield pairs abutting over their entire length interradially separated by a single plate similar in size and shape to radial shields.

EE 16207 (Fig. 4.2) is an articulated arm fragment composed of seven proximal to median segments; proximal segments similar to those of holotype; median arm segments becoming progressively more elongate; median LAPs without constriction and with smaller and less prominent spine articulations; arm spines of median segments as long as half an arm segment; tentacle pores large and developed as between-plate openings in two proximal-most segments; tentacle pores of the following segments developed as within-plate perforations, strongly decreasing in size and progressively moving from a ventral to a ventro-distal position toward the distal-most preserved segment; proximal-most within-plate tentacle perforation with two oval scales; following tentacle openings with no discernible scales; ventral arm plates strongly decreasing in size from proximal-most to distal-most preserved segment; the two proximal-most ones similar to those observed on holotype, the following ventral arm plates fan-shaped, wider than long.

EE 16208 (Fig. 4.3) is an articulated arm fragment composed of nine proximal to median arm segments; proximal ones similar to those of holotype, median ones more elongate; median LAPs devoid of constriction but with similar outer surface ornamentation as proximal lateral arm plates; dorsalmost spine articulations decreasing in size and moving from a nearly dorsal to a lateral position from the proximal-most to the distal-most preserved segments; arm spines of median segments equaling half the length of an arm segment; dorsal arm plates discernible on all preserved arm segments.

EE 16209 (Fig. 4.4), EE 16210 (Fig. 4.5), and EE 16211 (Fig 4.6) are dissociated proximal, median, and distal LAPs, respectively; rounded rectangular outline; proximal LAP nearly as long as high, distal one approximately 1.5 times wider than high; dorsal edge weakly concave, distal edge straight to very weakly convex; proximal edge deeply concave, devoid of discernible spurs but paralleled by deep, poorly defined furrow; weak horizontal striation near central part of furrow; outer surface ornamentation as in LAPs of holotype; four spine 


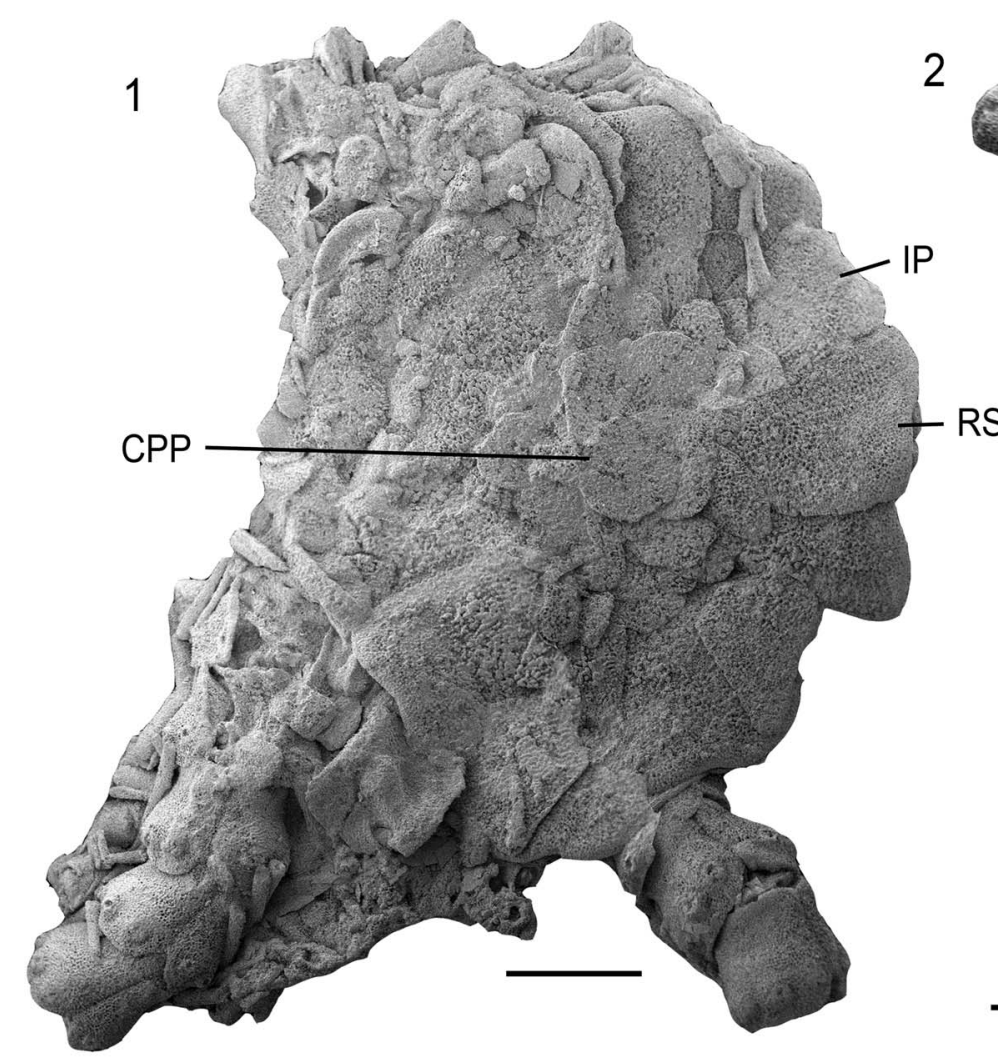

4.1

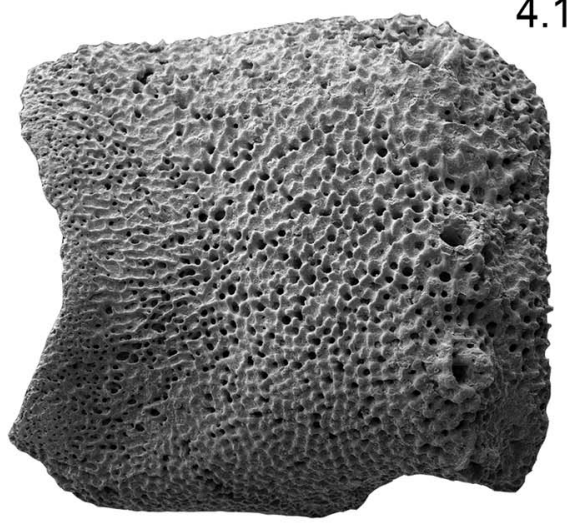

4.2

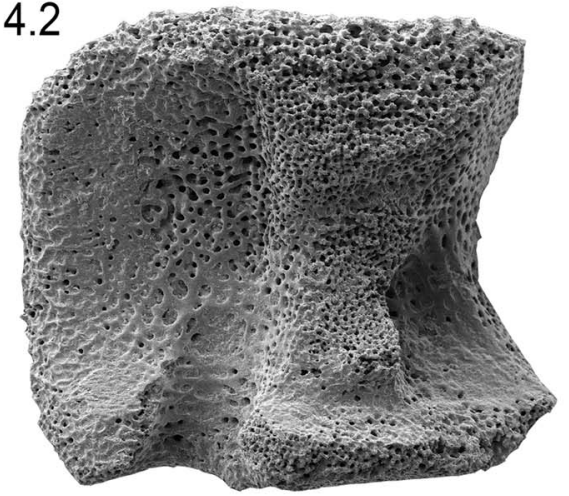

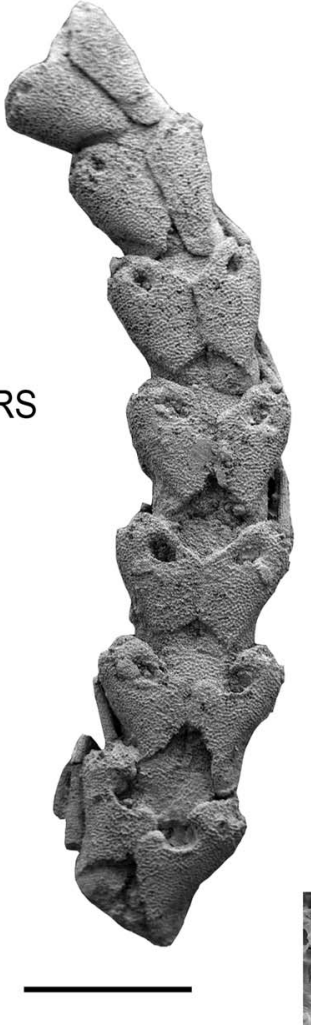

5.1

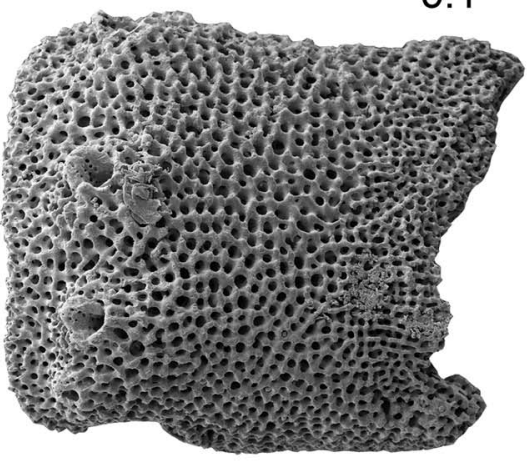

5.2

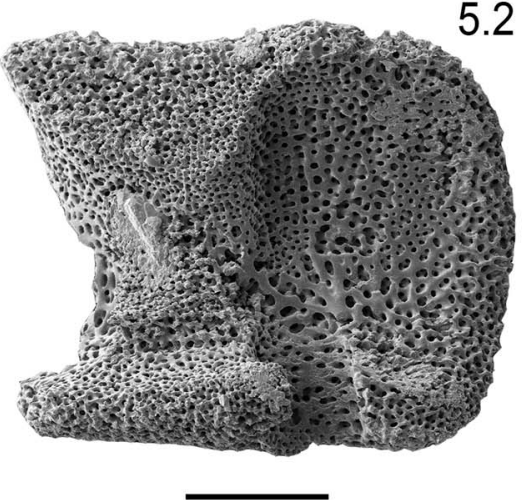

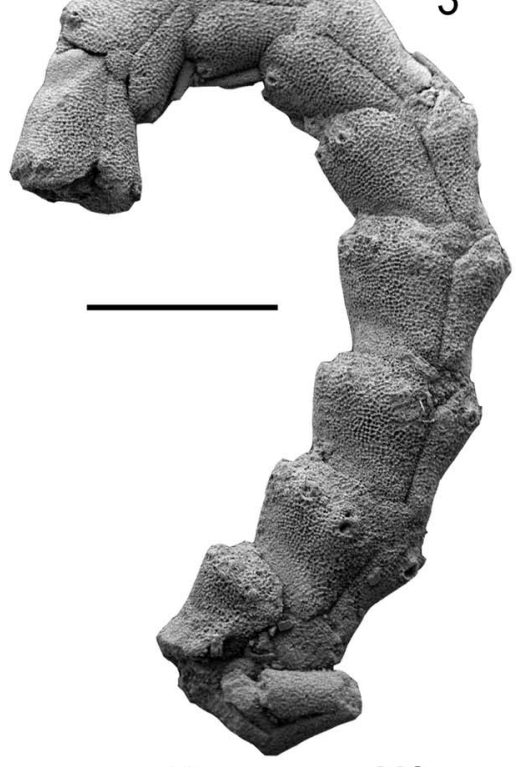

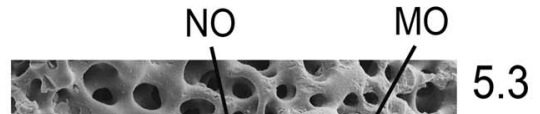

Figure 4. Enakomusium whymanae n. sp., Coln Quarry, Lechlade, Gloucestershire, UK 51.6951N, 1.7372W; ex situ layer of fissile gray shaly clay from the jason Zone, Peterborough Member, lower Oxford Clay, Callovian, late Middle Jurassic. (1) NHMUK EE 16206 (paratype), dorsal side of disk; (2) NHMUK EE 16207 (paratype), ventral side of arm fragment; (3) NHMUK EE 16208 (paratype), dorsal side of arm fragment; (4) NHMUK EE 16209 (paratype), proximal lateral arm plate in (4.1) external and (4.2) internal views; (5) NHMUK EE 16210 (paratype), median lateral arm plate in (5.1) external and (5.2) internal views and (5.3) with detail of spine articulation; (6) NHMUK EE 16211 (paratype), distal lateral arm plate in (6.1) external and (6.2) internal views. (1-3) Scale bars $=1 \mathrm{~mm} ;(\mathbf{4}, \mathbf{5 . 1}, \mathbf{5 . 2}, \mathbf{6})$ scale bar $=200 \mu \mathrm{m} ;(\mathbf{5 . 3})$ scale bar $=50 \mu \mathrm{m}$. CPP = central primary plate; IP $=$ interradial plate; $\mathrm{MO}=$ muscle opening; $\mathrm{NO}=$ nerve opening; $\mathrm{RS}=$ radial shield. 
articulations in proximal and median LAPs, three in distal one; spine articulations relatively large, prominent, on slightly elevated part of distal LAP portion, tightly encompassed by outer surface stereom; strong dorsalward increase in size of spine articulations and in distance separating them; spine articulation morphology as in holotype but better preserved. Inner side of LAPs with large, rounded triangular dorsal contact surface with opposite LAP; ventral contact surface much smaller; short, well-defined, prominent ridge in central part of inner side, with tongue-shaped, dorso-proximalward-pointing dorsal tip; inner side of distal LAP edge with slightly more densely meshed stereom but devoid of discernible spurs; proximal and median LAPs with large, deep, sharply defined ventralward-pointing tentacle notch; distal LAP with large tentacle perforation distally bordering the central ridge; no other perforations discernible.

Etymology.-Species named in honor of Janet Whyman (Coventry, United Kingdom), who discovered the type material and generously donated it to the Natural History Museum London.

Materials.-NHMUK EE 16206, EE 16207, EE 16208, EE 16209, EE 16210, EE 16211 (paratypes); NHMUK EE 15466 (28 complete specimens and a collection of several hundred arm and disk fragments).

Remarks.-The Ophiomusium-like form, with stout overall plating and at least part of the tentacle pores developed as within-plate openings, is one of the most widespread in Jurassic ophiuroids. The taxonomic status and systematic position of these forms was subject to considerable controversy, amendments of genus diagnoses, and the introduction of the regrettably misrouted genus Mesophiomusium Kutscher and Jagt, 2000 (Thuy and Meyer, 2013; Thuy, 2015). To put at least some of the Jurassic Ophiomusium-like forms on solid taxonomic ground, in accordance with the latest insights on ophiuroid morphology, Thuy (2015) introduced the genus Enakomusium to accommodate Ophiomusium-like forms with rounded rectangular LAPs, relatively large spine articulations bearing relatively long spines, and tentacle pores developed as betweenplate openings in proximal and often median arm segments.

The present material fully accords with the diagnosis of Enakomusium. Among the currently known species of the genus, it most closely resembles the type species E. weymouthiense (see below), particularly in respect to the radial shields, the single interradial plates, and the mouth plating. The present specimens differ, however, in their smaller size, a less robust plating, and particularly, possession of lateral arm plates with a constriction (Figs. 4.4 to 4.6) and larger, more prominent spine articulations that are not sunken into depressions and which bear spines that exceed the length of an arm segment. The LAPs of the here described material furthermore lack any discernible spurs on the outer distal edge, have a less well-defined furrow paralleling the distal edge, and are generally less robust. At least part of these differences cannot be explained by ontogenetic variation and thus preclude assignment to E. weymouthiense, despite their stratigraphical and geographical proximity.
Other species assigned to Enakomusium generally have stouter LAPs, smaller and less prominent spine articulations, and discernible spurs on the outer distal edge and therefore cannot be confused with the present material. It thus seems warranted to erect a new species. Within the morphological spectrum of Enakomusium, the new species is the least Ophiomusium-like, with the generally more fragile plating, the conspicuous and prominent spine articulations, and the unusually long arm spines. Modern representatives of the OphiomusiumOphiosphalma-Ophiolipus complex tend to be much more morphologically conservative. The Jurassic forms generally contrast with their modern relatives in showing a much larger range of morphologies, with the present one even superficially reminiscent of ophiacanthid morphologies with the large, prominent spine articulations, the constricted LAPs, and the long spines (e.g., Thuy, 2013).

\section{Enakomusium sp. indet.}

Materials.-LEIUG 73036. One specimen containing three poorly preserved articulated individuals and three sections of disarticulated arm.

Occurrence.- Stewartby quarry, Stewartby Brickworks, Bedford, Bedfordshire, UK Bed 6a (Duff), lower Oxford Clay, medea Subzone, jason Zone (Callovian), Middle Jurassic.

Remarks.-This poorly preserved specimen was figured by Martil and Hudson (1991). The articulated ophiuroids from the Peterborough Member of Stewartby, Great Britain, are too poorly preserved to enable a confident species-level identification. With respect to the few morphological features discernible on the specimens, assignment to Enakomusium seems warranted, and there are indeed superficial similarities to $E$. whymanae n. sp. from Coln Quarry, Gloucestershire, but we nevertheless prefer treating the specimens as an unidentified record of Enakomusium.

\section{Enakomusium weymouthiense (Damon, 1880)}

Figure 5.1-5.3

1880 Ophioderma weymouthiense Damon, plate 17, fig. 10, 10A.

1963 Ophiomusium calloviense Hess, p. 1143.

1964 Ophiomusium weymouthiense Hess, p. 780.

2015 Enakomusium weymouthiense Thuy, p. 95.

Materials.-NHMUK E 1607b (neotype), specimens figured by Hess (1964) from the same locality include E 1607a, E 3500. Eighteen other specimens from the Weymouth area containing over 50 individuals are also known in the NHM collections but did not provide any new information.

Description.-Redescription of the original LAPs of Hess (1963): LAPs moderately large, thick, proximal ones slightly higher than wide, distal ones slightly wider than high, rounded rectangular outline with very weakly convex dorsal and distal edges; proximal edge strongly concave, with two poorly defined, vertically elongate, thin spurs dorsally and a much 

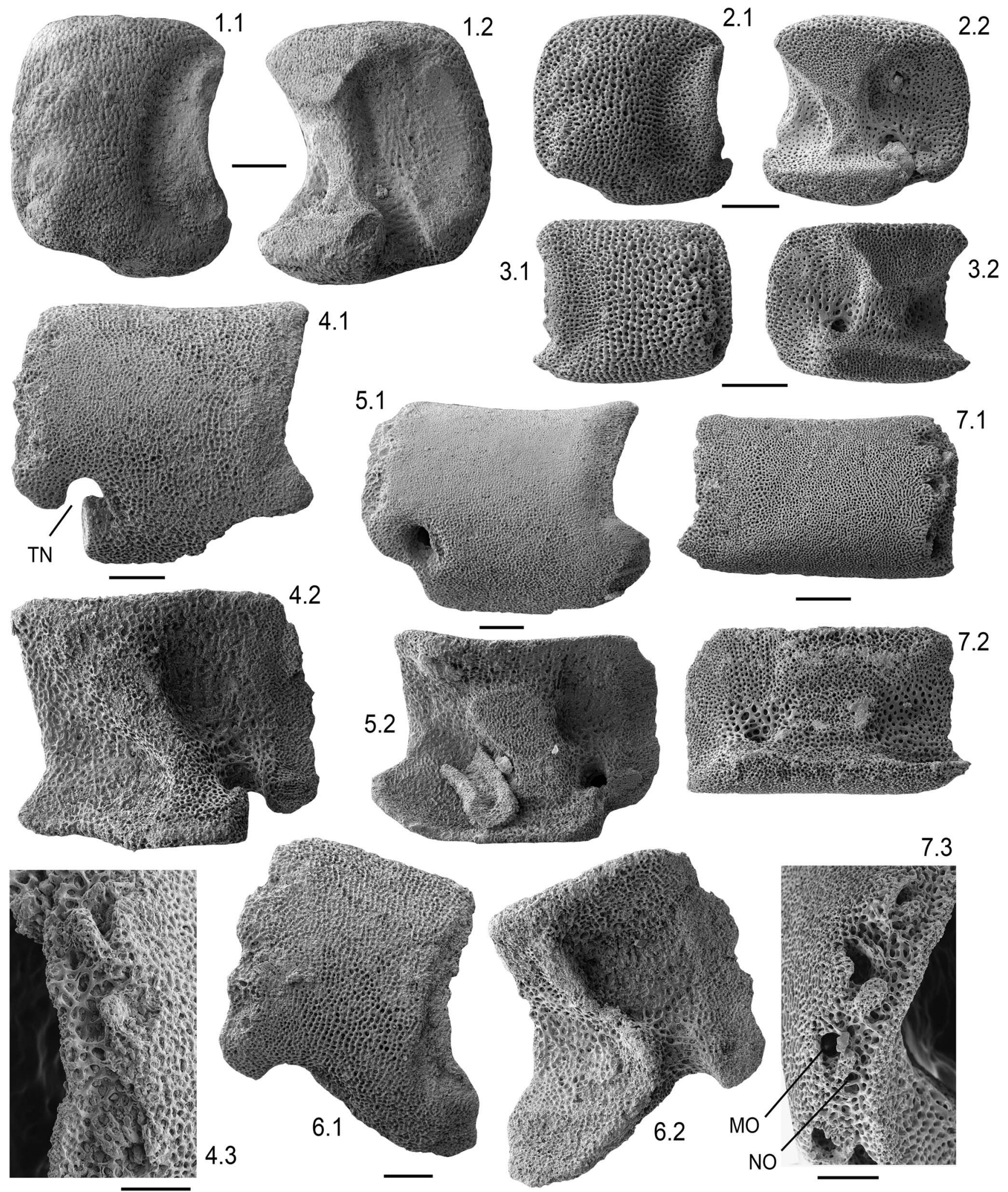

Figure 5. Enakomusium weymouthiense (Damon, 1880), Callovian of Liesberg, Switzerland, specimens from the original material of Hess (1963). (1) Proximal lateral arm plate in (1.1) external and (1.2) internal views; (2) median lateral arm plate in (2.1) external and (2.2) internal views; (3) distal lateral arm plate in (3.1) external and (3.2) internal views. Aspidophiura? seren new species, Coln Quarry, Lechlade, Gloucestershire, UK 51.6951N, 1.7372W; ex situ layer of fissile gray shaley clay from the jason Zone, Peterborough Member, lower Oxford Clay, Callovian, late Middle Jurassic. (4) NHMUK EE 16212 (holotype), proximal lateral arm plate in (4.1) external and (4.2) internal views and (4.3) with detail of spine articulations; (5) NHMUK EE 16213 (paratype), median lateral arm plate in (5.1) external and (5.2) internal views; (6) NHMUK EE 16214 (paratype), proximal lateral arm plate in (6.1) external and (6.2) internal views; (7) NHMUK EE 16215 (paratype), distal lateral arm plate in (7.1) external and (7.2) internal views and (7.3) with detail of spine articulations. (1-4.2, 4.4-7.2) Scale bars $=200 \mu \mathrm{m} ;(4.3,7.3)$ Scale bars $=100 \mu \mathrm{m} . \mathrm{MO}=$ muscle opening; $\mathrm{NO}=$ nerve opening; $\mathrm{TN}=$ tentacle notch . 
shorter, equally poorly defined spur ventrally; proximal edge paralleled by a conspicuous, deep furrow; distal half of ventral edge in proximal and median LAPs weakly concave; distal LAPs with evenly convex ventral edge. Outer surface stereom of LAPs moderately finely meshed and with weakly enlarged, vertically elongate, and densely packed trabecular intersections; faint horizontal striation lining the distal edge of the furrow paralleling the proximal LAP edge. Three to four relatively large spine articulations sunken in shallow depressions of the distal portion of the LAP at some distance from the distal edge and tightly encompassed by the outer surface stereom; strong dorsalward increase in the size of the spine articulations and the distance separating them; spine articulations composed of a large, round muscle opening proximally tightly encompassed by a relatively low, semicircular, irregularly denticulate ridge and distally separated from a slightly smaller nerve opening by a thicker, more prominent but shorter vertical oblique ridge composed of slightly more densely meshed stereom.

Inner side of LAPs with large ventral and dorsal contact surfaces with opposite LAP; short, wide, well-defined, and prominent central ridge on elevated part connecting the ventral and dorsal contact surfaces with the opposite LAP, widest ventrally and with a tongue-shaped, slightly proximalwardpointing dorsal tip; inner side of distal edge lined with poorly defined, very weakly prominent vertical surface composed of more densely meshed stereom; large, deep, sharply defined ventralward- (proximal LAPs) to ventro-distalward-pointing (median LAPs) tentacle notch; distal LAPs with large ventrodistalward-pointing tentacle perforation. No further perforations discernible on inner side.

Remarks.-The neotype and associated specimens were duly described and illustrated by Hess (1964). There is nothing to add from our observations of the type material. To facilitate comparison with other species, in particular those known exclusively from dissociated LAPs, we redescribe and illustrate the LAPs from the Callovian of Switzerland originally described by Hess (1963) as Ophiomusium calloviense and shortly after synonymized with Ophioderma (now Enakomusium) weymouthiense (Hess, 1964) using the terminology by Thuy and Stöhr (2011).

The LAPs of Enakomusium weymouthiense bear strong similarities with those described by Thuy (2015) as Enakomusium leckenbyi (Wright, 1880) and Enakomusium ferrugineum (Boehm, 1889), corroborating their assignment to the same genus (Thuy and Stöhr, 2011). The main difference put forward by Thuy (2015) was the grouped ventral spine articulations separated from the dorsal-most one by a gap. Our redescription suggests a strong but continuous dorsalward increase in the distance separating the spine articulations, rather than a ventral grouping and a dorsal gap. Another noteworthy difference with the LAPs of E. leckenbyi and E. ferrugineum is that the spine articulations of $E$. weymouthiense are sunken in shallow depressions. Differences with the new species Enakomusium whymanae are discussed in the preceding.

Occurrence.-Radipole Backwater or Ham Cliff, Weymouth, Dorset; Weymouth Member, early Oxfordian, Late Jurassic.
Genus Aspidophiura Matsumoto, 1915

Type species.-Aspidophiura watasei Matsumoto, 1915, by original designation

Aspidophiura? seren new species

Figure 5.4-5.7

\section{Holotype.-NHMUK EE 16212.}

Diagnosis.-Species with relatively large, nearly rectangular LAPs, wider than high, with slightly concave dorsal edge, finely meshed outer surface stereom with small trabecular intersections; smooth proximal edge; three to four spine articulations integrated in the distal edge of the LAPs; single, large central ridge on inner side; proximal LAPs with deep tentacle notch distally encompassed by a strongly protruding ventrodistal tip of the LAP; median and distal LAPs with a large tentacle perforation.

Occurrence.—Coln Quarry, Lechlade, Gloucestershire, UK $51.6951^{\circ} \mathrm{N}, 1.7372^{\circ} \mathrm{W}$; ex situ layer of fissile gray shaley clay from the jason Zone, Peterborough Member, lower Oxford Clay, Callovian, late Middle Jurassic.

Description of holotype.-EE 16212 (Fig. 5.4) is a dissociated proximal LAP of rectangular outline, slightly wider than high, with weakly concave dorsal edge, convex distal edge, and irregularly convex ventral edge; ventrodistal tip of LAP strongly protruding; proximal edge of LAP concave, smooth, devoid of discernible spurs, and with a narrow band of more finely meshed stereom; outer surface of LAP with finely meshed stereom with small trabecular intersections, no vertical or horizontal striations discernible. Three spine articulations sunken in distal edge of LAP, tightly encompassed by outer surface stereom, nearly of equal size; gap between the ventral and median spine articulations slightly larger than between the dorsal and the median ones; spine articulations composed of an irregularly shaped muscle opening proximally bordered by a thin, poorly defined, and weakly prominent vertical ridge and distally separated from the slightly smaller, round nerve opening by a large, prominent, well-defined, and straight vertical ridge.

Inner side of LAP with a single, large, well-defined oblique ridge, widest at rounded dorsal tip; ventral tip of ridge merged with ventral portion of LAP; dorsal and ventral contact surfaces with opposite LAP thin; inner side of distal edge smooth, with a poorly defined band of more finely meshed stereom; deep, sharply defined, ventralward-pointing tentacle notch almost completely encompassed by the slightly thickened ventrodistal edge of the LAP; no perforations discernible.

Paratype supplements.-EE 16213 (Fig. 5.6) is a dissociated proximal LAP, slightly wider than high, with a straight dorsal tip and strongly ventroproximalward-protruding ventral portion; proximal edge and outer surface as in holotype; spine articulation morphology as in holotype except for a larger gap between the dorsal and median spine articulations; tentacle notch deep but not as closely encompassed as in holotype; ridge on inner side of LAP narrower than in holotype. 
EE 16214 (Fig. 5.5) is a dissociated median LAP with width approximately 1.5 times height, with concave dorsal edge and evenly convex ventral edge; ridge on inner side wider than in holotype, with sharply defined ventral tip; tentacle opening large and completely encompassed by ventral portion of LAP.

EE 16215 (Fig. 5.7) is a dissociated distal LAP with width nearly two times height, with weakly concave dorsal edge and nearly straight ventral edge; four spine articulations as in holotype, with dorsalward decrease in size of gaps separating the spine articulations; ventral-most spine articulation distally bordered by the relatively small tentacle perforation; inner side with small but well-defined ridge.

Etymology.-After the welsh for star. In honor of the 'stellar' support received by the first author from Joanne V. Dallosso, Wales, United Kingdom.

Materials.-NHMUK EE 16213, EE 16214, EE 16215, EE 16216 (five dissociated LAPs).

Remarks.-The above described dissociated LAPs were found together with the remains of Enakomusium whymanae. The spine articulation morphology with the muscle and nerve openings separated by a vertical ridge in combination with the LAPs laterally encompassing the arm suggests an assignment to the ophiurid-Ophiomusium complex within clade A of O'Hara et al. (2014). Similarities with members of the OphiomusiumOphiosphalma-Ophiolipus complex are weaker due to the generally more fragile plate architecture and the thin dorsal and ventral contact surfaces with the opposite LAP. Most ophiurids have proximal LAPs that are higher than long and have typically distalward-pointing tentacle notches (Thuy and Stöhr, 2011). A few recent species, however, share the slightly elongate LAPs with almost completely encompassed tentacle notches in proximal LAPs and tentacle perforations in distal LAPs with the here described specimens. Among these, greatest similarities are shared with the LAPs of Aspidophiura forbesi (Duncan, 1879; Thuy, unpublished observations, 2016), although they differ from the present specimens in having a spur on the proximal edge, prominent spine articulations at some distance from the distal edge, and a much larger dorsal contact surface with the opposite LAP. The assignment of the present material to Aspidophiura should therefore be considered tentative, awaiting further advances in the analysis of the LAP morphologies of similar recent species.

No other fossil LAP type currently known shows the combination of characters displayed by the present material. Superficial similarities are shared with the LAPs of the articulated specimens from the Aptian of Antarctica described by Smith and Crame (2012) as Mesophiomusium paragraysonensis (Taylor, 1966), especially in terms of the relatively thin, rectangular LAPs and the development of the tentacle openings. Differences assessable on the basis of the figures published by Smith and Crame (2012) mainly pertain to the development of the ventrodistal edge of the LAPs. Whether M. paragraysonensis and the present material belong to the same genus cannot be decided from the evidence at hand. However, neither the present material nor the Aptian specimens in Smith and Crame (2012) are assignable to Mesophiomusium, whose type species is strongly reminiscent of modern Ophiomastus Lyman, 1878 (Thuy, 2015). For the time being, we therefore describe the present material as a new species tentatively assigned to the extant genus Aspidophiura, stressing, however, that the genus-level placement is likely to change with future advances in LAP morphology studies.

Clade B of O'Hara et al. (2014)

Genus Dermocoma Hess, 1964

Type species.-Dermocoma wright Hess, 1964, by original designation.

\section{Dermocoma species indet.} Figure 6

Description.-NHMUK E 54378 is an articulated disk (disk diameter $28.35 \mathrm{~mm}$ ) exposing both ventral and dorsal sides and preserving a portion of an arm composed of five proximal segments; disk outline slightly lobed interradially; dorsal disk scales moderately thick, round, imbricate, largely obscured by small, densely spaced removable granules; no variation of granule size or shape discernible on dorsal disk surface; radial shields (Fig. 6.2) also completely covered by disk granules, rounded isosceles triangular in outline, widely separated, accounting for approximately one-third of the disk radius.

Interradial areas of ventral disk slightly protruding, covered by small, rounded, imbricate scales completely obscured by removable granules similar to those of the dorsal disk side; genital slit accounting for at least one-third of the disk radius; oral shields (Fig. 6.3) conspicuous, not covered by granules, approximately as wide as long, with nearly right proximal angle, rounded lateral angles, and a slightly angular convex distal edge; one oral shield slightly larger and thicker than the other four and with proximally pointed depression in the middle of the distal portion, thus probably identifiable as madreporite; adoral shields (Fig. 6.3) narrow, abutting near proximal tip of oral shield, extending around the lateral angles of the oral shield; adoral shields and oral plates covered by removable granules larger than disk granules and slightly elongate; up to seven oval lateral oral papillae (Fig. 6.3), contiguous, becoming smaller and more conical toward the distal tip of the oral plates; two to three apical oral papillae, of similar size as proximal-most lateral oral papillae but more conical; ventral-most teeth two to three times as large as apical oral papillae, rounded triangular; first ventral arm plate with width two times length, oval, with longitudinal central depression.

Only proximal-most arm segments preserved, weakly noded, wider than long and nearly as high as wide; LAPs (Fig. 6.6) with very weak constriction, evenly convex distal edge, and ventrodistalward-protruding ventral portion; proximal edge not observable; outer surface with irregular but welldeveloped vertical striation, consisting of weakly imbricate vertical lamellae, fining and eventually fading into a finely meshed stereom toward the proximal edge of the LAP; six large, ear-shaped spine articulations in notches of elevated distal portion of the LAPs, proximally bordered by outer surface striation, with dorsalward increase in size of spine articulations and of gaps separating them; spine articulations with continuous volute and well-developed sigmoidal fold; arm spines (Fig. 6.6) 

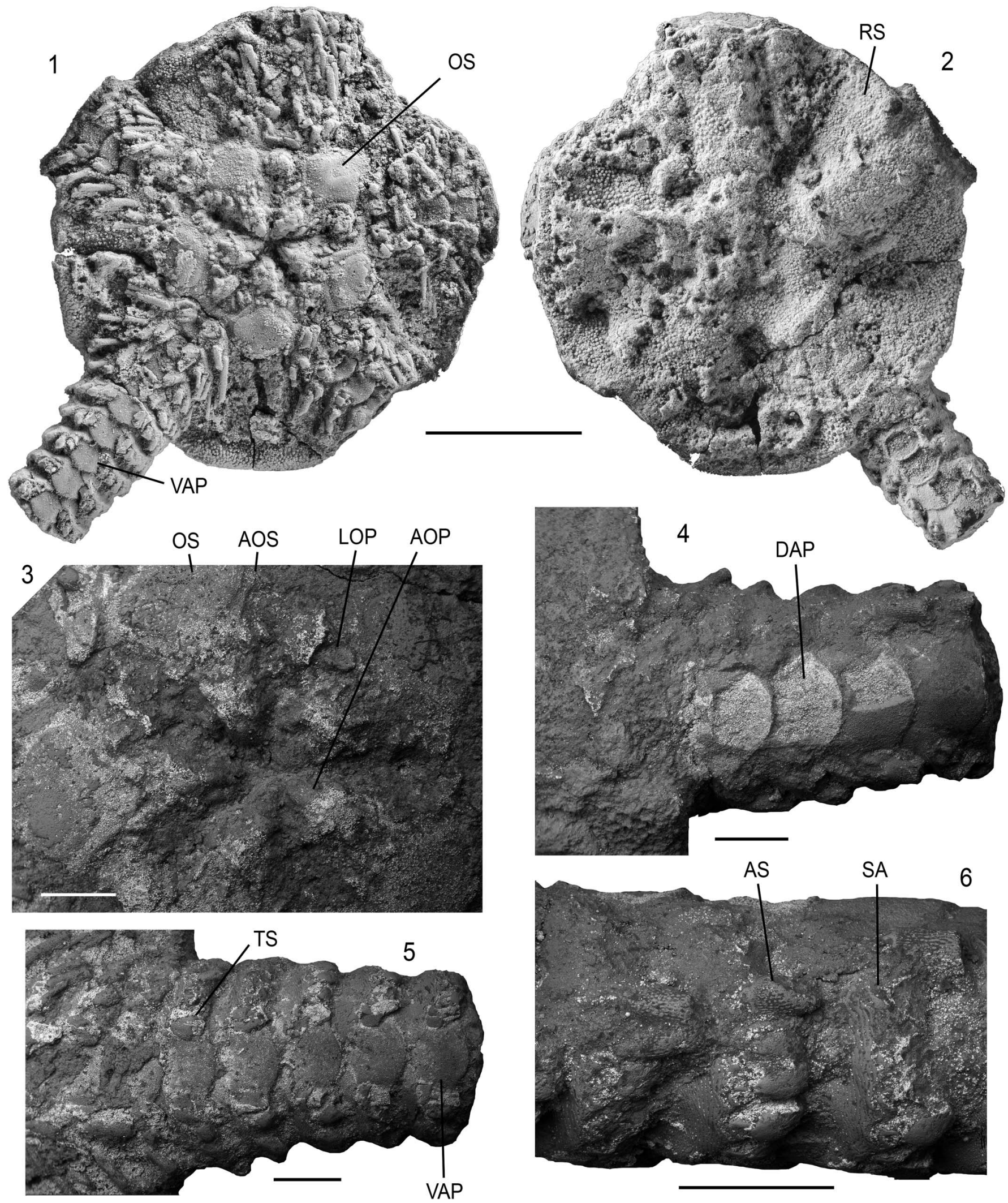

Figure 6. Dermocoma species indet., NHMUK E 54378, The Fleet, Weymouth, Dorset; Weymouth Member, early Oxfordian, Late Jurassic. (1) Ventral side of disk; (2) dorsal side of disk; (3) detail of mouth plating; (4) dorsal side of proximal-most arm segments; (5) ventral side of proximalmost arm segments; (6) lateral side of proximal-most arm segments. Scale bars are $(\mathbf{1}, \mathbf{2})$ Scale bar $=5 \mathrm{~mm} ;(\mathbf{3 - 6})$ scale bars $=1 \mathrm{~mm}$. AOP $=$ apical oral papilla; AOS $=$ adoral shield; AS = arm spine; DAP = dorsal arm plate; $\mathrm{LOP}=$ lateral oral papilla; OS = oral shield; RS = radial shield; $\mathrm{SA}=$ spine articulation; TS = tentacle scale; $\mathrm{VAP}=$ ventral arm plate. 
large, conical, with coarsely reticulate outer surface, maximum length unknown; inner side of LAPs unknown; dorsal arm plates (Fig. 6.4) large, in contact on all preserved arm segments, widest distally, with strongly convex distal edge and straight proximalward-converging lateral edges, proximal tip unknown; ventral arm plates (Fig. 6.5) nearly as wide as long, separated by LAPs from the third freestanding arm segment, with convex distal edge, concave lateral edges, and obtuse proximal angle; two leaf-shaped, nearly equal-sized distalward-pointing tentacle scales.

\section{Materials.-NHMUK E 54378.}

Remarks.-The large, ear-shaped spine articulations with the well-developed sigmoidal fold, in combination with a vertical striation on the outer LAP surface and two to three small, apical oral papillae, unambiguously place the present specimen among the members of the family Ophiacanthidae as formerly understood (e.g., Thuy, 2013). Within this group, the densely granulated disk, the rounded triangular radial shields, the relatively small tentacle openings, the large, contiguous proximal dorsal arm plates, the ventroproximalward-protruding ventral portion of the LAPs, and the regularly spaced spine articulations positioned in notches of the elevated distal LAP portion strongly favor assignment to the extinct genus Dermocoma. Hess (1964) introduced the genus on the basis of articulated ophiuroids from the Bathonian of Malmesbury, Wiltshire, United Kingdom. The genus was recently assigned to the family Ophiacanthidae and thoroughly reassessed by Thuy (2015), who transferred a number of previously known species to Dermocoma and identified numerous new species, thus showing the genus to be one of the most speciose fossil ophiacanthids.

Among the currently known species of Dermocoma, only D. toarcensis (Hess, 1962) from the Toarcian of Switzerland, D. longwyensis Thuy, 2013 from the Bajocian of France, and D. numbergerorum Thuy, 2013 from the Oxfordian of France have up to six spine articulations. The inaccessibility of the outer proximal edge and the inner side of the LAPs in the here-described specimen precludes a thorough comparison with the three previously described species. In D. longwyensis, the LAPs are generally much smaller and have an undulose outer surface striation. The LAPs of $D$. numbergerorum have a conspicuously long ventral portion. Similarities are greatest with the LAPs of $D$. toarcensis, although the large stratigraphical gap make an assignment to the species unlikely.

Chances are high that the present specimen belongs to an undescribed species of Dermocoma. Despite its exceptional preservation, however, it cannot be formally described here in the absence of more detailed knowledge of its LAP morphology. Pending the discovery of more insightful material, the specimen is reported here as a member of an ophiuroid group previously unknown from the Oxford Clay and as a new find of an articulated disk assignable to the extinct Dermocoma.

Occurrence.-The Fleet, Weymouth, Dorset; Weymouth Member, early Oxfordian, Late Jurassic.
Genus Ophiotitanos Spencer, 1907

Type species.-Ophiotitanos tenuis Spencer, 1907, by original designation.

\section{Ophiotitanos smithi new species}

Figure 7

1880 Amphiura prattii Forbes, 1844; Wright, p. 158, pl. 18, fig. 1a-d.

1964 Ophiochiton? pratti (Forbes); Hess, p. 796.

Holotype.-NHMUK 24682.

Diagnosis.-Species of Ophiotitanos with stout dorsal disk plating, rounded isosceles-triangular radial shields with slightly concave lateral edges; no trace of removable granules on the disk plates; large, thick, plectrum-shaped oral shields; lateral arm plates with finely meshed stereom with small trabecular intersections; spine articulations on slightly thickened distal portion of LAP; conspicuous dorsalward increase in size of spine articulations and of gaps separating them; large, pointed, slightly flattened arm spines slightly shorter than one arm segment.

Occurrence.-Christian Malford, NE Chippenham, Wiltshire; phaeinum Subzone, athleta Zone, upper part of the Peterborough Member, Oxford Clay Formation, late Callovian, Middle Jurassic.

Description.-NHMUK 24682 is a nearly complete articulated individual (disk diameter of $27.10 \mathrm{~mm}$ ) exposing both ventral and dorsal sides and preserving parts of five arms, three of which include proximal to median segments; dorsal disk has rather thick, rounded, irregularly shaped disk scales; central and radial primary plates indistinguishable from disk scales; radial shields thick, rounded isosceles-triangular, with very weakly concave lateral edges, accounting for approximately half the disk radius, separated by five disk scales; no removable granules discernible.

Ventral side of disk with interradial areas covered by small, round, moderately thick scales; no removable granules discernible; genital slit simple and accounting for at least one-third of the disk radius; oral shields (Fig. 7.2) conspicuous, plectrum-shaped with rounded acute proximal angle, wider, strongly convex distal edge, and convex lateral edges; adoral shields (Fig. 7.2) poorly preserved, straight, with pointed proximal tip, seemingly not abutting near proximal tip of oral shield; oral plates stout; at least six oval to leaf-shaped lateral oral papillae (Fig. 7.2), contiguous, decreasing in size toward the proximal tip of the oral plates; three leaf-shaped, pointed apical oral papillae; teeth unknown; first ventral arm plate with width 2.5 times height, with incised proximal edge and pointed distal edge.

Arms stout, with relatively short, high proximal segments and slightly longer and lower median segments; proximal LAPs (Fig. 7.5) higher than wide, devoid of a constriction, with convex distal edge and ventroproximalward-protruding ventral portion; proximal edge of LAPs not observable; outer surface with very finely meshed stereom and small trabecular 

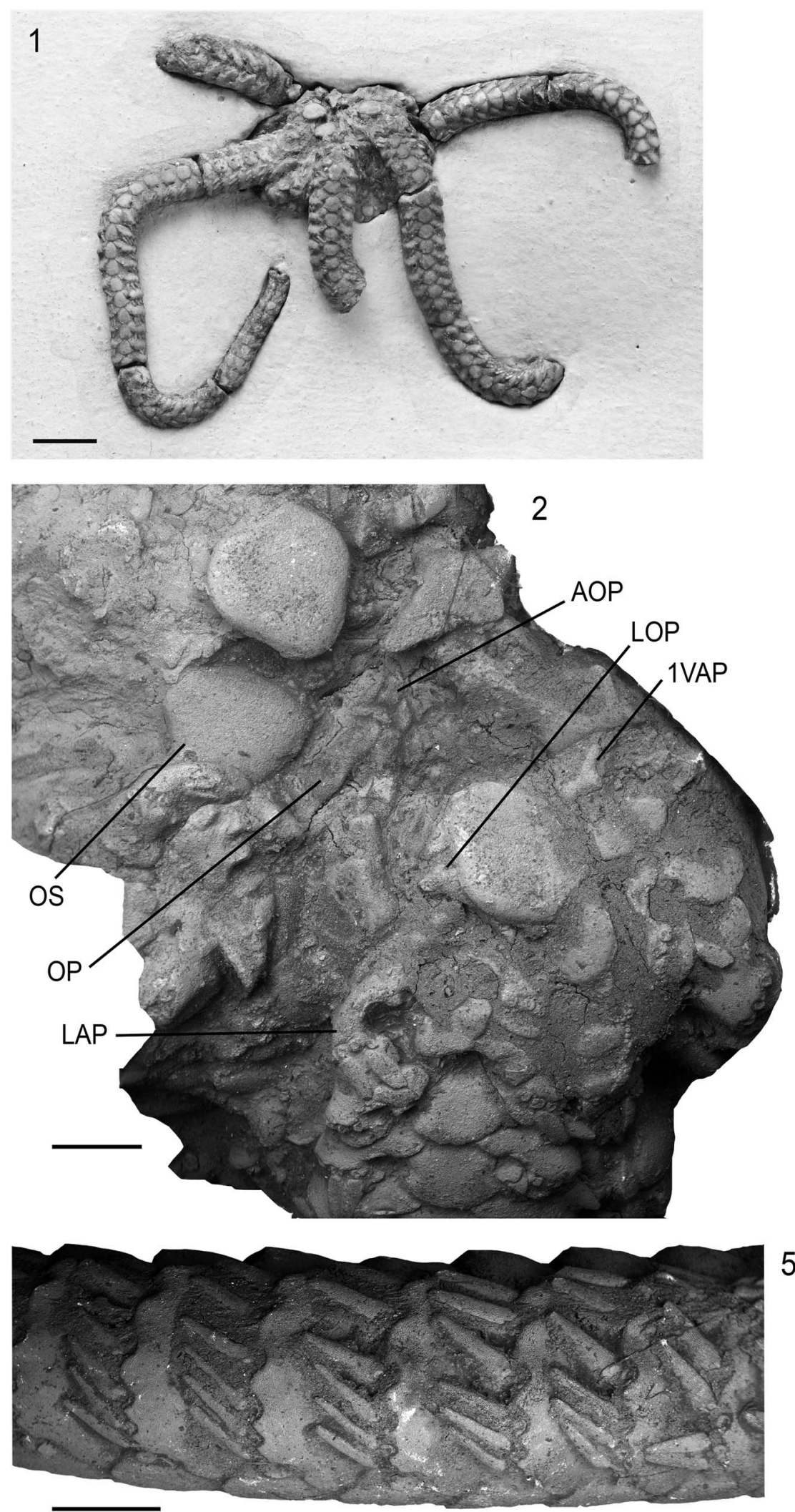
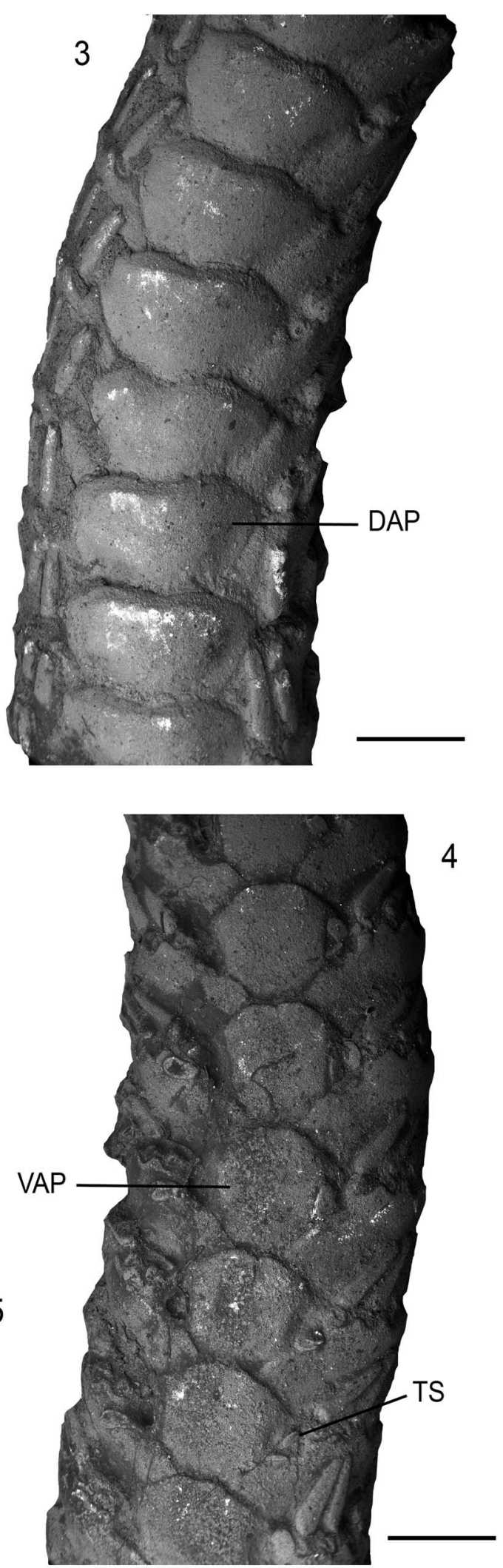

Figure 7. Ophiotitanos smithi n. sp., NHMUK 24682 (holotype), Christian Malford, NE Chippenham, Wiltshire; phaeinum Subzone, athleta Zone, upper part of the Peterborough Member, Oxford Clay Formation, late Callovian, Middle Jurassic. (1) Ventral side of disk; (2) detail of mouth plating; (3) dorsal side of proximal arm segments; (4) ventral side of proximal arm segments; (5) lateral side of proximal arm segments. (1) Scale bar $=5 \mathrm{~mm} ;(\mathbf{2 - 5}) \mathrm{scale}$ bars $=1 \mathrm{~mm}$. $\mathrm{AOP}=$ apical oral papilla; $\mathrm{DAP}=$ dorsal arm plate; $\mathrm{LAP}=$ lateral arm plate; $\mathrm{LOP}=$ lateral oral papilla; $\mathrm{OS}=\mathrm{oral}$ shield; $\mathrm{OP}=$ oral $\mathrm{plate} ; \mathrm{TS}=$ tentacle scale; VAP = ventral arm plate; $1 \mathrm{VAP}=$ first ventral arm plate. 
intersections, no striation discernible; up to six spine articulations in deep notches of distal edge, proximally sharply bordered by slightly thickened outer surface stereom; spine articulations slightly oblique, composed of a crescent-shaped dorsal lobe and a slightly smaller and lower similarly crescentshaped ventral lobe merged proximally into a continuous, dorsoventrally flattened volute and distally connected by a weakly developed sigmoidal fold; muscle opening slightly larger than nerve opening; conspicuous but regular dorsalward increase in size of spine articulations and of gaps separating them; arm spines stout, pointed, slightly flattened, with very small scale-like ornamentation on outer surface, almost as long as an arm segment and with dorsalward increase in thickness but not in length; inner side of LAPs unknown. Dorsal arm plates (Fig. 7.3) very large, wider than high, widest distally, with incised distal edge and slightly convex, proximalwardconverging lateral edges, proximal edge not observable; dorsal arm plates widely separating LAPs in all observable arm segments. Ventral arm plates (Fig. 7.4) nearly as wide as long, irregularly hexagonal, with strongly obtuse distal angle and truncated distal tip, slightly concave lateral edges, and proximalward-converging latero-proximal edges; proximal tip of ventral arm plates unknown; tentacle openings small, covered by two small, oval scales.

Etymology.-Species named in honor of Andrew B. Smith (Kelso, Scotland, United Kingdom), one of the most influential echinoderm paleontologists of the last few decades, in recognition of his enthusiasm to promote research on ophiuroid evolution.

Materials.-Only the holotype NHMUK 24682.

Remarks.-The present specimen was originally published by Wright (1880) but misidentified as Amphiura pratti Forbes, 1844. Hess (1964) redescribed the specimen in detail but also considered it as another specimen of $A$. pratti, which he tentatively transferred to the extant genus Ophiochiton. It is interesting to note that Hess (1964) mentioned a superficial similarity between specimen 24682 and the Cretaceous ophiodermatid Ophiotitanos tenuis Spencer, 1907. Indeed, the spine articulation morphology of the present specimen leaves no doubt as to its ophiodermatid affinities.

Fossil ophiodermatids were generally assigned to extant genera, in particular the type genus Ophioderma Müller and Troschel, 1840. Thuy (2015), however, argued that most of the fossil ophiodermatid reported, in fact, belong to a different genus: Ophiotitanos. The present specimen is no exception in this respect. Its LAP morphology, in particular the conspicuous dorsalward increase in size of the spine articulations and of the gaps separating them, the low number of spine articulations, the long, stout arm spines, and the seeming absence of removable granules on the disk plates and scales preclude assignment to any currently known extant ophiodermatid. Ophiotitanos and in particular its type species $O$. tenuis still await a thorough reassessment in terms of higher systematics and phylogenetic relation with modern ophiodermatids. For the time being, however, it seems best to treat the present specimen as another Jurassic record of Ophiotitanos.
On the species level, the specimen described herein stands out in having rounded isosceles-triangular radial shields with slightly concave lateral edges and, most important, in having LAPs with a strong dorsalward increase in size of the spine articulations and of the gaps separating them, a pattern found in no other currently known species of Ophiotitanos or related forms assigned to other genera. We thus consider it a new species.

Clade C of O'Hara et al. (2014)

Genus Ophioplax Lyman, 1875

Type species.-Ophioplax ljungmani Lyman, 1875, by original designation.

Ophioplax pratti (Forbes, 1844)

Figure 8

1880 Amphiura prattii Forbes, 1844, figs. 49, 50.

1964 Ophiochiton? pratti (Forbes); Hess, p. 796.

Material._BGS 3096 A (holotype).

Remarks.-The type specimen of A. pratti was duly redescribed and figured by Hess (1964). Our reexamination of the holotype yielded no further insights with respect to the poorly preserved disk skeleton (Fig. 8.1). As for the arms, however, scanning electron microscopy revealed previously overlooked but diagnostically significant microstructural characters. The spine articulations (Fig. 8.2, 8.3) were already found by Hess (1964) to be horseshoe-shaped. We can now show that the dorsal and ventral lobes of the spine articulation are proximally connected by three to four small, slightly elongate spurs. In combination with a finely meshed outer surface stereom with very small, inconspicuous trabecular intersections, the spine articulation morphology strongly suggests assignment to the extant genus Ophioplax, albeit tentatively.

With the reidentification of specimen EE 24682 as an ophiodermatid, the only currently known specimen of Ophioplax pratti is the holotype. Its poor preservation, in particular with respect to the accessibility of the LAPs, unfortunately precludes a comprehensive comparison with other fossil occurrences of the Ophioplax-Ophiodoris group (e.g., Thuy et al., 2013; Thuy, 2015). Proper characterization of the holotype would require a more thorough investigation of the LAP morphology, which is difficult to obtain without damaging the type. We therefore treat $O$. pratti as a valid species, stressing, however, that the present state of knowledge precludes any systematic conclusions beyond genus level.

Occurrence.-Christian Malford, NE Chippenham, Wiltshire; phaeinum Subzone, athleta Zone, upper part of the Peterborough Member, Oxford Clay Formation, late Callovian, Middle Jurassic.

\section{Paleoecological considerations}

While ophiuroids are not the most iconic fossils of the British Oxford Clay, locally they can occur in great numbers and constitute a reasonable component of the Oxford Clay benthos. 

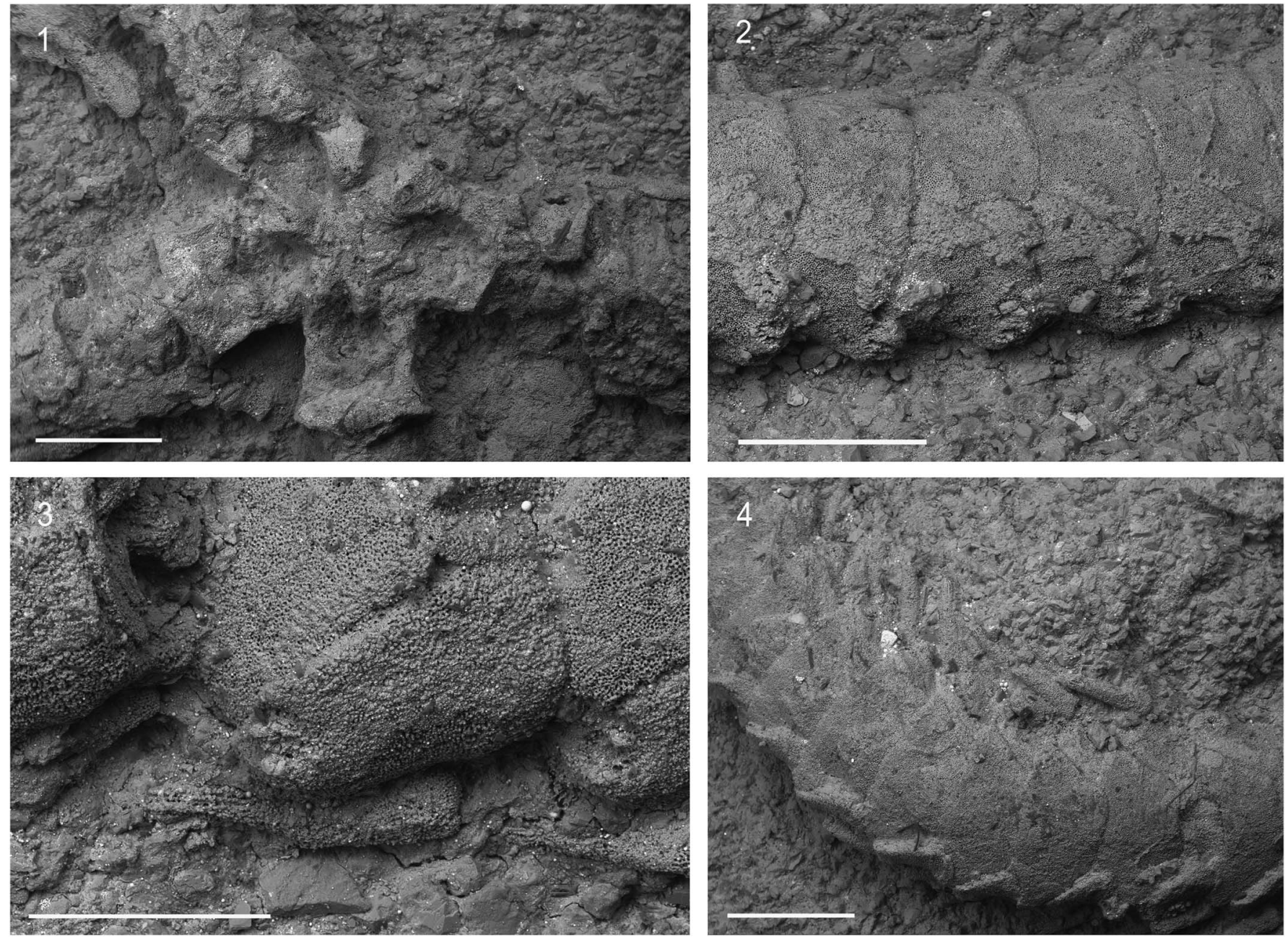

Figure 8. Ophioplax pratti (Forbes, 1844), BGS 3096 A, Christian Malford, NE Chippenham, Wiltshire; phaeinum Subzone, athleta Zone, upper part of the Peterborough Member, Oxford Clay Formation, late Callovian, Middle Jurassic. (1) Detail of dorsal disk; (2) dorsal side of proximal arm segments; (3) detail of proximal arm segments in dorsolateral view; (4) dorsal side of median arm segments. $(\mathbf{1}, \mathbf{3}, \mathbf{4})$ Scale bars $=1 \mathrm{~mm} ;(\mathbf{2})$ scale bar $=500 \mu \mathrm{m}$.

Previous reports clearly underrated the Oxford Clay ophiuroid diversity. Thanks to new finds and a critical reassessment of historic records, the total number of species for the Oxford Clay Formation has increased from two to six.

The ophiuroid species identified in the present study includes two assemblages, one from the middle Callovian Peterborough Member consisting of Enakomusium whymanae and Aspidophiura seren, and the monospecific assemblage of Enakomusium weymouthiense from the lower Oxfordian Weymouth Member, as well as the single occurrences of Ophiotitanos smithi, Ophioplax pratti, Enakomusium sp., and Dermocoma sp. Of interest, occurrences consisting of more than a single articulated specimen are dominated by or entirely composed of Enakomusium species. Since the preservation of articulated ophiuroid skeletons generally precludes major transport, this observation suggests that members of Enakomusium, in contrast to the other Oxford Clay ophiuroid species, lived in dense aggregations. With its long arm spines and the generally rather stout arms, Enakomusium whymanae was most probably an epibenthic suspension feeder. Dense aggregations of suspension-feeding ophiuroids are nowadays most common in (but not restricted to) bathyal settings (e.g., Metaxas and Giffin, 2004). Along with the mostly bathyal depth range of recent members of closely related genera Ophiomusium and Ophiosphalma (Thuy and Meyer, 2013), the here described assemblage of Enakomusium whymanae represents a nonactualistic ophiuroid occurrence and adds to the evidence that crown group ophiuroids have undergone fundamental changes in distribution since the Jurassic (e.g., Thuy et al., 2013).

Among the very few Callovian ophiuroid communities known to date, the Oxford Clay ophiuroid faunal spectrum is most similar to the Callovian assemblages recovered from erratic boulders found in North Germany (Kutscher, 1987) and furthermore accords well with previously known Oxfordian shallow-water assemblages, especially those from mud bottoms, many of which are dominated by Enakomusium (e.g., Hess, 1975).The assemblages from La Voulte, France (Hess, 1960) and Liesberg, Switzerland (Hess, 1963), by contrast, are dominated by ophioleucid taxa. Ophiotitanos and Ophioplax (or the closely related Ophiodoris) have not been reported from the Callovian before, but since both forms are known from the Bajocian (Thuy, 2015) and the Oxfordian (Thuy et al., 2013; Thuy, 2015), their occurrence in the Callovian is not surprising. The occurrence of an Aspidophiura-like species adds to the growing record of ophiurids in the Jurassic. 
Thus, the Callovian and Oxfordian ophiuroid occurrences described herein are in line with previous records and seem to be part of the typical faunal spectrum of upper Middle to lower Upper Jurassic mud-bottom ophiuroid communities from midshelf depths. The material nevertheless stands out as it almost entirely consists of articulated skeletons and thus provides unpreceded insights into the morphology of the concerned taxa. They are among the very few cases in which exceptionally preserved ophiuroid fossils represent more than single-taxa occurrences (e.g., Thuy et al., 2011).

Taphonomically, the finds described herein almost all represent cases of articulated preservation. Dissociated LAPs, by contrast, were so far only recovered accidentally as bycatch within the set of articulated specimens of Enakomusium whymanae. The overrepresentation of articulated specimens in the studied material is without any doubt due to sampling bias. Systematic sieving of Oxford Clay sediments is very likely to produce more occurrences of dissociated LAPs.

The ophiuroids that inhabited the Peterborough Member were all found in fine, dark to medium gray or olive green, fissile shales. This suggests that the ophiuroids were probably overwhelmed by distal obrution events while living in warm, relatively deep seas (i.e., below storm wave base) in open marine conditions but with periodic seafloor euroxia. The remains of Aspidophiura seren are an exception here in consisting of completely dissociated arm plates found via screen washing among the articulated remains of Enakomusium whymanae. This hints that this species was allochthonous or that the remains were autochthonous and disarticulated before burial. There is also little (if any) indication of arm regeneration among the Peterborough Member ophiuroids. However, this is as likely due to the sample size, collection method (sieving of much of the material), and taphonomy as it is a true biological signal or low predation.

Of the two species originating from the Weymouth Member, there is no surviving lithological evidence with the Dermocoma specimen, and so further comment is impossible. However, the large number of E. weymouthensis specimens known are all preserved in a coarse, light gray-green, crossbedded silt and appear to have been buried by a more proximal obrution event. Indeed, this locality was the most proximal (to land) of all the English Oxford Clay ophiuroid localities known (see the preceding). There are also several incidences of arm regeneration within this population (approximately 1:10 have regenerating arms). Many modern ophiuroids autotomize their arms as a defensive measure against predation; they sacrifice an arm but the rest of the animal is left unscathed. Thus, if a population has a large number of regenerating individuals, it can be an indication of predation pressure (e.g., Aronson, 1991). This appears to be infrequent in the Weymouth ophiuroids.

\section{Acknowledgments}

We thank J. Whyman for the kind donation of fossils; K. Duff, N. Hollingworth, and D. Martill for helpful comments, information, and advice; and P. Sheppard (British Geological Survey) and C. Watts (Leicester University) for access to collections. We are indebted to the reviewers D. B. Blake (UrbanaChampaign, Illinois, USA) and S. Stöhr (Stockholm, SE), whose comments greatly improved an earlier version of this manuscript.

\section{References}

Aronson, R.B., 1991, Predation, physical disturbance, and sublethal arm damage in ophiuroids: A Jurassic-Recent comparison: Marine Ecology Progress Series, v. 74, p. 91-97.

Boehm, G., 1889, Ein Beitrag zur Kenntnis fossiler Ophiuren: Bericht der naturforschenden Gesellschaft, Freiburg im Breisgau, v. 4, p. 232-287.

Cox, B.M., and Page, K.N., 2002, Shipmoor Point-Butterstreet Cove and Tidmoor Point-East Fleet Coast, Dorset, in Cox, B.M., and Sumbler, M.G., eds., British Middle Jurassic Stratigraphy: Geological Conservation Review Series, v. 26, p. 20-29.

Cox, B.M., and Sumbler, M.G., 2002, British Middle Jurassic Stratigraphy: Geological Conservation Review Series, v. 26, 508 p.

Damon, R., 1880, Supplement to the Geology of Weymouth and the Isle of Portland, (second edition): London, 2 p.

Duff, K.L., 1974, Studies on the palaeontology of the lower Oxford clay of southern England [Ph.D. thesis]: University of Leicester, http://hdl.handle. net/2381/35016.

Duff, K.L., 1975, Paleoecology of a bituminous shale-The Lower Oxford Clay of central England: Palaeontology, v. 18, p. 443-482.

Duncan, P.M., 1879, On some Ophiuroidea from the Korean Seas: Journal of the Linnean Society, v. 14, p. 445-482.

Ewin, T.A.M., and Thuy, B., 2015, Two new British Mesozoic Ophiuroid localities, preliminary observations and determinations, in Zamora S., and Rábano I., eds., Progress in Echinoderm Palaeobiology: Madrid, Instituto Geológico y Minero de España, p. 53-57.

Forbes, E., 1844, On the fossil remains of starfishes and of the order Ophiuridae, found in Britain: Proceedings of the Geological Society of London, v. 4, p. 232-234.

Gray, J.E., 1840, A synopsis of the genera and species of the class Hypostoma (Asterias Linnaeus): Annals and Magazine of Natural History, v. 6, p. 175-184.

Hess, H., 1960, Neubeschreibung von Geocoma elegans (Ophiuroidea) aus dem unteren Callovien von La Voulte-sur-Rhône (Ardèche): Eclogae geologicae Helvetiae, v. 53, p. 335-385.

Hess, H., 1962, Mikropaläontologische Untersuchungen an Ophiuren II: Die Ophiuren aus dem Lias (Pliensbachien-Toarcien) von Seewen (Kt. Solothurn): Eclogae geologicae Helvetiae, v. 55, p. 609-656.

Hess, H., 1963, Mikropaläontologische Untersuchungen an Ophiuren III: Die Ophiuren aus dem Callovien-Ton von Liesberg (Berner Jura): Eclogae geologicae Helvetiae, v. 56, p. 1141-1164.

Hess, H., 1964, Die Ophiuren des englischen Jura: Eclogae Geologicae Helvetiae, v. 57, p. 756-801.

Hess, H., 1975, Mikropaläontologische Untersuchungen an Ophiuren VII: Die Ophiuren aus den Humeralis-Schichten (Ober-Oxford) von Raedersdorf (Ht-Rhin): Eclogae geologicae Helvetiae, v. 68, p. 603-612.

Hudson, J.D., and Martill, D.M., 1994, The Peterborough Member (Callovian, Middle Jurassic) of the Oxford Clay Formation at Peterborough, UK: Journal of the Geological Society, London, v. 151, p. 113-124.

Hudson, J.D., Taylor, M.A., Duff, K.L., Riding, J.B., and Brown, P.R., 1994 The trophic structure of the biota of the Peterborough Member (Oxford Clay Formation, Middle Jurassic) of central England: Journal of the Geological Society, London, v. 151, p. 173-194.

Kutscher, M., 1987, Die Echinodermen der Callovien-Geschiebe: Der Geschiebe-Sammler, v. 2-3, p. 53-104.

Kutscher, M., and Jagt, J.W.M., 2000, Early Maastrichtian ophiuroids from Rügen (northeast Germany) and Mon (Denmark), in Jagt, J.M.W. Late Cretaceous-Early Paleocene echinoderms and the K/T boundary in the southeast Netherlands and the northeast Belgium, part 3: Ophiuroids, Scripta Geologica, v. 21, p. 45-107.

Lyman, T., 1875, Zoological results of the Hassler expedition. 2. Ophiuridae and Astrophytidae: Illustrated Catalogue of the Museum of Comparative Zoology at Harvard College, v. 8, no. 2, p. 1-34. 5 pl.

Lyman, T., 1878, Ophiuridae and Astrophytidae of the "Challenger" expedition. Part I: Bulletin of the Museum of Comparative Zoology at Harvard College, Cambridge, Massachusetts, v. 5, no. 7, p. 65-168.

MacQuaker, J.H.S., 1994, A lithofacies study of the Peterborough Member, Oxford Clay Formation (Jurassic), UK: An example of sediment bypass in a mudstone succession: Journal of the Geological Society, v. 151, no. 1, p. $161-172$.

Martill, D.M., and Hudson, J.D., eds., 1991, Fossils of the Oxford Clay: London, The Palaeontological Association, Field Guide to Fossils, v. 4, 286 p.

Martill, D.M., Taylor, M.A., Duff, K.L., Riding, J.B., Bown, P.R., and Hudson, J.D., 1994, The trophic structure of the biota of the Peterborough Member, Oxford Clay Formation (Jurassic), UK: Journal of the Geological Society, London, v. 151, p. 173-194. 
Martynov, A., 2010, Reassessment of the classification of the Ophiuroidea (Echinodermata), based on morphological characters. I. General character evaluation and delineation of the families Ophiomyxidae and Ophiacanthidae: Zootaxa, v. 2697, p. 1-154.

Matsumoto, H., 1915, A new classification of the Ophiuroidea: With description of new genera and species: Proceedings of the Academy of Natural Sciences of Philadelphia, v. 68, p. 43-92.

Metaxas, A., and Giffin, B., 2004, Dense beds of the ophiuroid Ophiacantha abyssicola on the continental slope off Nova Scotia, Canada: Deep-Sea Research I, v. 51, p. 1307-1317.

Müller, J., and Troschel, F.H., 1840, Über die Ophiuren: Archiv für Naturgeschichte, v. 6, no. 1, p. 326-330.

O'Hara, T.D., Hugall, A.F., Thuy, B., and Moussalli, A., 2014, Phylogenomic resolution of the Class Ophiuroidea unlocks a global microfossil record: Current Biology, v. 24, p. 1-6.

Page, K.N., 2002, Ham Cliff, Redcliff Point, Dorset (SY 713 817), in Cox, B.M., and Sumbler, M.G., eds., British Middle Jurassic Stratigraphy: Geological Conservation Review Series, v. 26, 508 p.

Smith, A.B., and Crame, A., 2012, Echinoderm faunas from the Lower Cretaceous (Aptian-Albian) of Alexander Island, Antarctica: Palaeontology, v. 55, no. 2, p. 305-324.

Smith, A.B., Paterson, G.L.J., and Lafay, B., 1995, Ophiuroid phylogeny and higher taxonomy: Morphological, molecular and palaeontological perspectives: Zoological Journal of the Linnean Society, v. 114, p. 213-243.

Spencer, W.K., 1907, A monograph of the British fossil Echinodermata from the Cretaceous formations: The Asteroidea and Ophiuroidea: Paleontographical Society Monographs, v. 2, no. 4, p. 91-132.

Stöhr, S., O'Hara, T.D., and Thuy, B., 2012, Global diversity of brittle stars (Echinodermata: Ophiuroidea): PLoS One, v. 7, no. 3, e31940 doi: 10.1371/ journal.pone.0031940.

Taylor, B.J., 1966, Taxonomy and morphology of Echinodermata from the Aptian of Alexander Island: British Antarctic Survey Bulletin, v. 8, p. 1-18.

Thuy, B., 2013, Temporary expansion to shelf depths rather than an onshoreoffshore trend: The shallow-water rise and demise of the modern deep-sea brittle star family Ophiacanthidae (Echinodermata: Ophiuroidea): European Journal of Taxonomy, v. 48, p. 1-242.

Thuy, B., 2015, A peri-reefal brittle-star (Echinodermata, Ophiuroidea) assemblage from the Middle Jurassic of the northeast Paris Basin: Ferrantia Travaux Scientifiques du Musée national d'histoire naturelle, v. 71, p. 87-106.
Thuy, B., and Meyer, C.A., 2013, The pitfalls of extrapolating present-day depth ranges to fossil communities: New insights from brittle stars (Echinodermata: Ophiuroidea) from the Middle Jurassic of Switzerland: Swiss Journal of Palaeontology, v. 132, p. 5-21.

Thuy, B., and Stöhr, S., 2011, Lateral arm plate morphology in brittle stars (Echinodermata: Ophiuroidea): New perspectives for ophiuroid micropalaeontology and classification: Zootaxa, v. 3013, p. 1-47.

Thuy, B., and Stöhr, S., 2016, A new morphological phylogeny of the Ophiuroidea (Echinodermata) accords with molecular evidence and renders microfossils accessible for cladistics: PLoS One, v. 11, no. 5, e0156140 doi: 10.1371/journal.pone.0156140.

Thuy, B., Gale, A.S., and Reich, M., 2011, A new echinoderm Lagerstätte from the Pliensbachian (Early Jurassic) of the French Ardennes: Swiss Journal of Palaeontology, v. 130, p. 173-185.

Thuy, B., Gale, A.S., Kroh, A., Kucera, M., Numberger-Thuy, L.D., Reich, M. and Stöhr, S., 2012, Ancient origin of the modern deep-sea fauna: PLoS One, v. 7, no. 10, e46913.

Thuy, B., Marty, D., and Comment, G., 2013, A remarkable example of a Late Jurassic shallow-water ophiuroid assemblage from the Swiss Jura Mountains: Swiss Journal of Geosciences, v. 106, p. 409-426.

Westaway, R., Scotney, P.M., Younger, P.L., and Boyce, A.J., 2015, Subsurface absorption of anthropogenic warming of the land surface: The case of the world's largest brickworks (Stewartby, Bedfordshire, UK): Science of the Total Environment, v. 508, p. 585-603.

Wilby, P.R., Hudson, J.D., Clements, R.G., and Hollingworth, N.T.J., 2004 Taphonomy and origin of an accumulate of soft-bodied cephalopods in the Oxford Clay Formation (Jurassic, England): Palaeontology, v. 47, no. 5, p. 1159-1180.

Wilby, P.R., Duff, K., Page, K., and Martin, S., 2008, Preserving the unpreservable: A lost world rediscovered at Christian Malford, UK: Geology Today, v. 24 , p. $95-98$.

Wright, T., 1880, Monograph of the British fossil Echinodermata from the oolithic formations. Volume 2 - The Asteroidea and Ophiuroidea. Part 3: Monograph of the Palaeontographical Society, v. 1880, p. 155-203.

Wright, J.K., and Cox, B.M., 2001, British Upper Jurassic stratigraphy (Oxfordian to Kimmeridgian): Peterborough, Joint Nature Conservation Committee, Geological Conservation Review, v. 21, p. 266.

Accepted 6 December 2016 